\title{
8
}

\section{The Origins of Aesthetics: A Neurobiological Basis for Affective Feelings and Aesthetics}

\author{
Edmund T. Rolls
}

In this chapter a theory of the origins of aesthetics is described. This has its roots in emotion, in which what is pleasant or unpleasant, a reward or punisher, is the result of an evolutionary process in which genes define the (pleasant or unpleasant) goals for action (Rolls 2005b). It is argued that combinations of multiple such factors provide part of the basis for aesthetics. To this is added the operation of the reasoning, syntactic, brain system which evolved to help solve difficult, multistep, problems, and the use of which is encouraged by pleasant feelings when elegant, simple, and hence aesthetic solutions are found that are advantageous because they are parsimonious, and follow Occam's Razor. The combination of these two systems, and the interactions between them, provides an approach to understanding aesthetics that is rooted in evolution and its effects on brain design and function.

I start by considering how affective value is generated in the brain as a solution to the problem of how genes can specify useful goals for actions. This is more efficient and produces more flexible behaviour than by specifying the actions themselves. Then, in Sections 5 and 6, I develop this theory further into a theory of the origins of aesthetics.

\section{Emotions as states elicited by rewards and punishers}

Emotions can usefully be defined (operationally) as states elicited by rewards and punishers that have particular functions (Rolls 1999, 2005b). The functions are defined below, and include working to obtain or avoid the rewards and punishers. A reward is anything for which an animal (which includes humans) will work. A punisher is anything that an animal will escape from or avoid. An example of an emotion might thus be happiness produced by being given a reward, such as a pleasant touch, praise, or winning a large sum of money. Another example of an emotion might be fear 
produced by the sound of a rapidly approaching bus, or the sight of an angry expression on someone's face. We will work to avoid such stimuli, which are punishing. Another example would be frustration, anger, or sadness produced by the omission of an expected reward such as a prize, or the termination of a reward such as the death of a loved one. Another example would be relief, produced by the omission or termination of a punishing stimulus such as the removal of a painful stimulus, or sailing out of danger. These examples indicate how emotions can be produced by the delivery, omission, or termination of rewarding or punishing stimuli, and go some way to indicate how different emotions could be produced and classified in terms of the rewards and punishments received, omitted, or terminated. A diagram summarizing some of the emotions associated with the delivery of reward or punishment or a stimulus associated with them, or with the omission of a reward or punishment, is shown in Fig. 8.1.

Before accepting this approach, we should consider whether there are any exceptions to the proposed rule. Are any emotions caused by stimuli, events, or remembered events that are not rewarding or punishing? Do any rewarding or punishing stimuli not

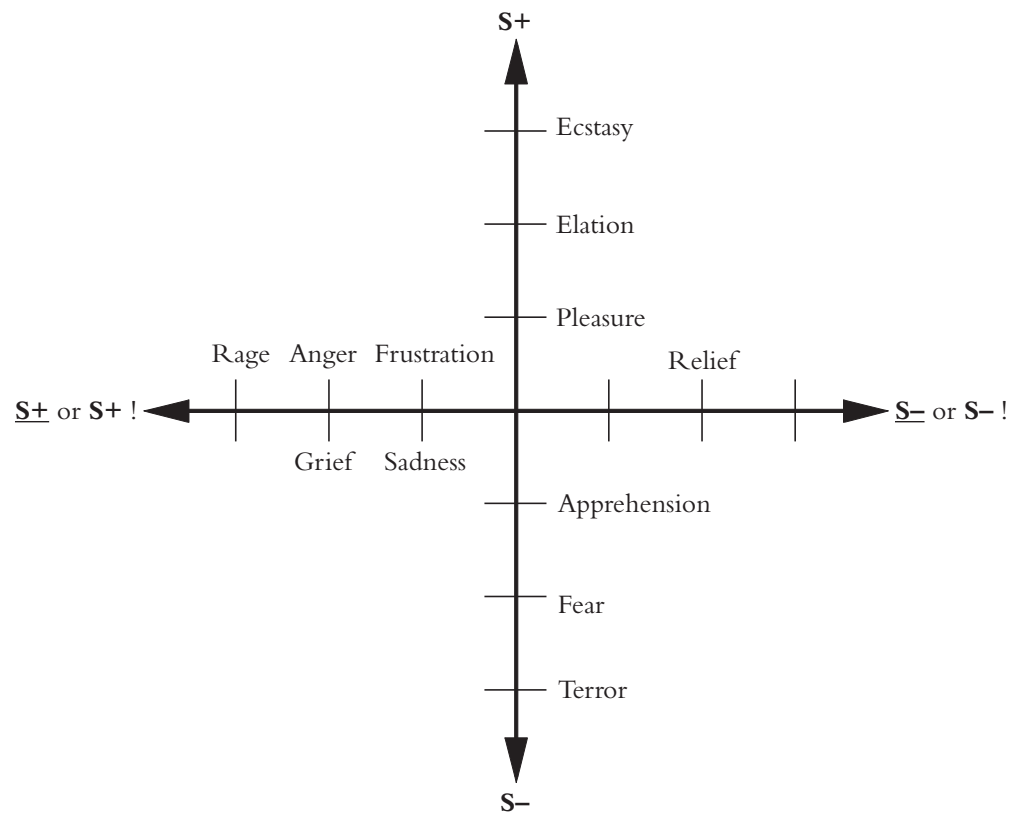

Figure 8.1 Some of the emotions associated with different reinforcement contingencies are indicated. Intensity increases away from the centre of the diagram, on a continuous scale. The classification scheme created by the different reinforcement contingencies consists of (1) the presentation of a positive reinforcer $(\mathrm{S}+),(2)$ the presentation of a negative reinforcer $(\mathrm{S}-)$, (3) the omission of a positive reinforcer $(\underline{S+})$ or the termination of a positive reinforcer $(\mathrm{S}+$ !), and (4) the omission of a negative reinforcer $(\underline{\mathrm{S}}-)$ or the termination of a negative reinforcer $(\mathrm{S}-$ !) 
cause emotions? We will consider these questions in more detail below. The point is that if there are no major exceptions, or if any exceptions can be clearly encapsulated, then we may have a good working definition at least of what causes emotions. Moreover, it is worth pointing out that many approaches to or theories of emotion (Strongman 1996) have in common that part of the process involves 'appraisal' (Frijda 1986; Lazarus 1991; Oatley and Jenkins 1996). In all these theories the concept of appraisal presumably involves assessing whether something is rewarding or punishing. The description in terms of reward or punishment adopted here seems more tightly and operationally specified. I next consider a slightly more formal definition than rewards or punishments, in which the concept of reinforcers is introduced, and show how there has been a considerable history in the development of ideas along this line.

The proposal that emotions can be usefully seen as states produced by instrumental reinforcing stimuli follows earlier work by Millenson (1967), Weiskrantz (1968), Gray (1975, 1987), and Rolls (1986a, 1986b, 1990, 1999, 2000, 2005b). (Instrumental reinforcers are stimuli which, if their occurrence, termination, or omission is made contingent upon the making of a response, alter the probability of the future emission of that response.) Some stimuli are unlearned reinforcers (e.g., the taste of food if the animal is hungry, or pain); while others may become reinforcing by learning, because of their association with such primary reinforcers, thereby becoming 'secondary reinforcers'. This type of learning may thus be called 'stimulusreinforcement association', and occurs via a process like classical conditioning. If a reinforcer increases the probability of emission of a response on which it is contingent, it is said to be a 'positive reinforcer' or 'reward'; if it decreases the probability of such a response it is a 'negative reinforcer' or 'punisher'. For example, fear is an emotional state which might be produced by a sound (the conditioned stimulus) that has previously been associated with an electric shock (the primary reinforcer).

The converse reinforcement contingencies produce the opposite effects on behaviour. The omission or termination of a positive reinforcer ('extinction' and 'time out' respectively, sometimes described as 'punishing') decreases the probability of responses. Responses followed by the omission or termination of a negative reinforcer increase in probability, this pair of negative reinforcement operations being termed 'active avoidance' and 'escape' respectively (Rolls 2005b).

This foundation has been developed (see Rolls 1986a, 1986b, 1990, 1999, 2000, 2005 b) to show how a very wide range of emotions can be accounted for, as a result of the operation of a number of factors, including the following:

1. The reinforcement contingency (e.g., whether reward or punishment is given, or withheld) (see Fig. 8.1).

2. The intensity of the reinforcer (see Fig. 8.1).

3. Any environmental stimulus might have a number of different reinforcement associations. (For example, a stimulus might be associated both with the presentation of a reward and of a punisher, allowing states such as conflict and guilt to arise.) 
Table 8.1 Examples of primary reinforcers, and the dimensions of the environment to which they are tuned

These reinforcers, rewards and punishers, are gene-defined goals for action, and are associated with affective states.

\section{Taste}

Salt taste

Sweet

Bitter

Sour

Umami

Tannic acid

\section{Odour}

Putrefying odour

Pheromones

\section{Somatosensory}

Pain

Touch

Grooming

Washing

Temperature

\section{Visual}

Snakes, etc.

Youthfulness

Beauty

Secondary sexual

characteristics

Face expression

Blue sky, cover, open space

Flowers

\section{Auditory}

Warning call

Aggressive vocalization

Soothing vocalization

\section{Reproduction}

Courtship

Sexual behaviour

Mate guarding reward in salt deficiency

reward in energy deficiency

punisher, indicator of possible poison

punisher

reward, indicator of protein; produced by monosodium glutamate and inosine monophosphate punisher, it prevents absorption of protein; found in old leaves; probably somatosensory rather than strictly gustatory

punisher; hazard to health reward (depending on hormonal state)

punisher

reward

reward; to give grooming may also be a primary reinforcer reward

reward if tends to help maintain normal body temperature; otherwise punisher

punisher for, e.g., primates

reward, associated with mate choice

reward

rewards

reward (e.g., smile) and punisher (e.g., threat)

reward, indicator of safety

reward (indicator of fruit later in season?)

punisher

punisher

reward (part of the evolutionary history of music, which at least in its origins taps into the channels used for the communication of emotions)

reward

reward (a number of different reinforcers, including a low waistto-hip ration, and attractiveness influenced by symmetry and being found attractive by members of the other sex) reward for a male to protect his parental investment; jealousy results if his mate is courted by another male, because this may ruin his parental investment 
Table 8.1 Continued

Nest building

Parental attachment

Infant attachment to parents

Crying of infant

\section{Other}

Novel stimuli

Sleep

Altruism to genetically related individuals

Altruism to other individuals

Group acceptance

Control over actions

Play

Danger, stimulation, excitement

Exercise

Mind reading

Solving an intellectual problem

Storing, collecting

Habitat preference, home, territory

Some responses reward (when expecting young)

reward

reward

punisher to parents; produced to promote successful development

rewards (encourage animals to investigate the full possibilities of the multidimensional space in which their genes are operating) reward; minimizes nutritional requirements and protects from danger reward (kin altruism)

reward while the altruism is reciprocated in a 'tit-for-tat' reciprocation (reciprocal altruism); punisher when the altruism is not reciprocated

reward (social greeting might indicate this)

reward

reward

reward if not too extreme (adaptive because practice?)

reward (keeps the body fit for action)

reward; practice in reading others' minds, which might be adaptive

reward (practice in which might be adaptive)

reward (e.g., food)

reward

reward (e.g., pecking in chickens, pigeons; adaptive because it is a simple way in which eating grain can be programmed for a relatively fixed type of environmental stimulus)

4. Emotions elicited by stimuli associated with different primary reinforcers will be different. A list of some primary reinforcers to illustrate some of the different affective states that can be produced by them is provided in Table 8.1.

5. Emotions elicited by different secondary reinforcing stimuli will be different from each other (even if the primary reinforcer is similar).

6. The emotion elicited can depend on whether an active or passive behavioural response is possible. (For example, if an active behavioural response can occur to the omission of a positive reinforcer, then anger might be produced, but if only passive behaviour is possible, then sadness, depression or grief might occur.) 
By combining these six factors, it is possible to account for a very wide range of emotions (for elaboration see Rolls 2005b). It is also worth noting that emotions can be produced just as much by the recall of reinforcing events as by external reinforcing stimuli; and that cognitive processing (whether conscious or not) is important in many emotions, for very complex cognitive processing may be required to determine whether or not environmental events are reinforcing. Indeed, emotions normally consist of cognitive processing which analyses the stimulus, and then determines its reinforcing valence; and then an elicited mood change if the valence is positive or negative. In that an emotion is produced by a stimulus, philosophers say that emotions have an object in the world, and that emotional states are intentional, in that they are about something. We note that a mood or affective state may occur in the absence of an external stimulus, as in some types of depression, but that normally the mood or affective state is produced by an external stimulus, with the whole process of stimulus representation, evaluation in terms of reward or punishment, and the resulting mood or affect being referred to as emotion.

It is worth raising the issue that some philosophers categorize fear in the example as an emotion, but not pain. The distinction they make may be that primary (unlearned or innate) reinforcers (for example pain) do not produce emotions, whereas secondary reinforcers (stimuli associated by stimulus-reinforcement learning with primary reinforcers) do. (An example is fear, which is a state produced by a secondary reinforcing stimulus such as the sight of an image associated by learning with a primary reinforcer such as pain.) They describe the pain as a sensation. But neutral stimuli (such as a table) can produce sensations when touched. Thus whether a stimulus produces a sensation or not does not seem to be a useful distinction that has anything to do with affective or emotional states. It accordingly seems to be much more useful to categorize stimuli according to whether they are reinforcing (in which case they produce emotions or affective states, produced by both primary and secondary reinforcers), or are not reinforcing (in which case they do not produce emotions or affective states such as pleasantness or unpleasantness). Clearly there is a difference between primary reinforcers and learned reinforcers; but this is most precisely caught by noting that this is the difference, and that it is whether a stimulus is reinforcing that determines whether it is related to affective states and emotion. These points are considered in more detail by Rolls (2005b), who provides many examples of primary versus secondary reinforcers, all of which elicit affective states.

\section{The functions of emotion}

The functions of emotion also provide insight into the nature of emotion. These functions, described more fully elsewhere (Rolls 1990, 1999, 2005b), can be summarized as follows: 
1. The elicitation of autonomic responses (e.g., a change in heart rate) and endocrine responses (e.g., the release of adrenaline). These prepare the body for action.

2. Flexibility of behavioural responses to reinforcing stimuli. Emotional (and motivational) states allow a simple interface between sensory inputs and action systems. The essence of this idea is that goals for behaviour are specified by reward and punishment evaluation. When an environmental stimulus has been decoded as a primary reward or punishment, or (after previous stimulus-reinforcer association learning) a secondary rewarding or punishing stimulus, then it becomes a goal for action. The person can then perform any action (instrumental response) to obtain the reward, or to avoid the punisher. Thus there is flexibility of action, and this is in contrast with stimulus-response, or habit, learning in which a particular response to a particular stimulus is learned. The emotional route to action is flexible not only because any action can be performed to obtain the reward or avoid the punishment, but also because the person can learn in as little as one trial that a reward or punishment is associated with a particular stimulus, in what is termed 'stimulus-reinforcer association learning'.

To summarize and formalize, two processes are involved in the actions being described. The first is stimulus-reinforcer association learning, and the second is instrumental learning of an operant response made to approach and obtain the reward or to avoid or escape from the punisher. Emotion is an integral part of this, for it is the state elicited in the first stage, by stimuli which are decoded as rewards or punishers, and this state has the property that it is motivating. The motivation is to obtain the reward or avoid the punisher, and animals must be built to obtain certain rewards and avoid certain punishers. Indeed, primary or unlearned rewards and punishers are specified by genes which effectively specify the goals for action. This is the solution which natural selection has found for how genes can influence behaviour to promote their fitness (as measured by reproductive success), and for how the brain could interface sensory systems to action systems, and is an important part of Rolls' theory of emotion (1990, 1999, 2005b).

Selecting between available rewards with their associated costs, and avoiding punishers with their associated costs, is a process that can take place both implicitly (unconsciously), and explicitly using a language system to enable long-term plans to be made (Rolls 2005a, 2008b). These many different brain systems, some involving implicit evaluation of rewards, and others explicit, verbal, conscious, evaluation of rewards and planned long-term goals, must all enter into the selector of behaviour (see Fig. 8.2). This selector is poorly understood, but it might include a process of competition between all the competing calls on output, and might involve the anterior cingulate cortex and basal ganglia in the brain (Rolls 2005b, 2008b) (see Fig. 8.2). 


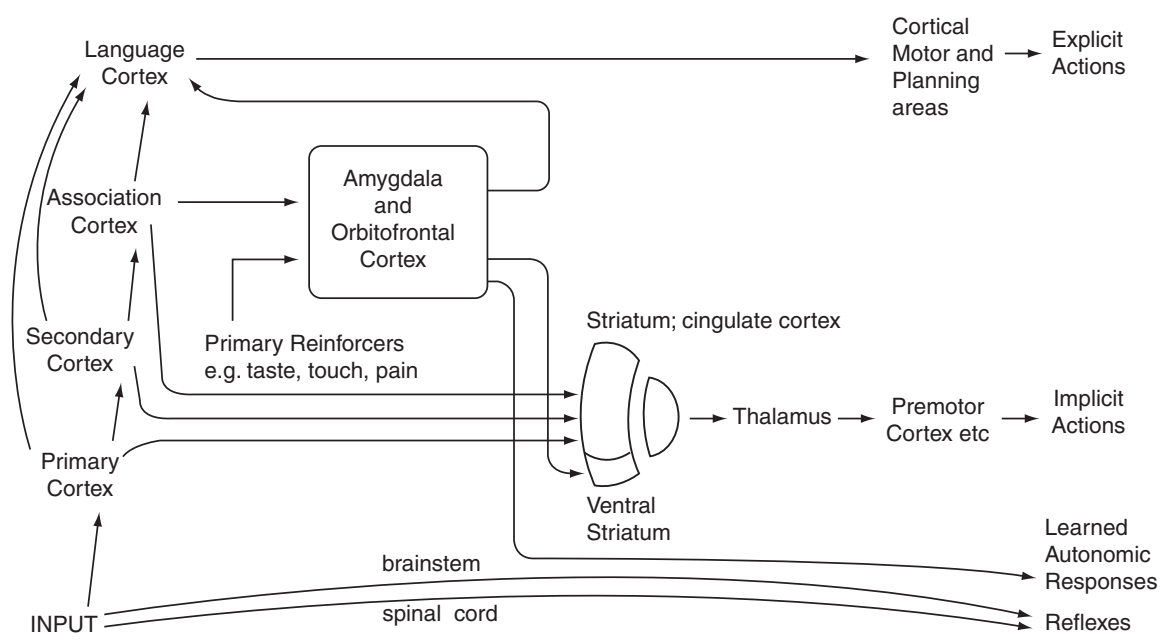

Figure 8.2 Dual routes to the initiation of action in response to rewarding and punishing stimuli. The inputs from different sensory systems to brain structures such as the orbitofrontal cortex and amygdala allow these brain structures to evaluate the reward- or punishment-related value of incoming stimuli, or of remembered stimuli. The different sensory inputs enable evaluations within the orbitofrontal cortex and amygdala based mainly on the primary (unlearned) reinforcement value for taste, touch, and olfactory stimuli, and on the secondary (learned) reinforcement value for visual and auditory stimuli. In the case of vision, the 'association cortex' which outputs representations of objects to the amygdala and orbitofrontal cortex is the inferior temporal visual cortex. One route for the outputs from these evaluative brain structures is via projections directly to structures such as the basal ganglia (including the striatum and ventral striatum) to enable implicit, direct behavioural responses based on the reward- or punishmentrelated evaluation of the stimuli to be made. The second route is via the language systems of the brain, which allow explicit decisions involving multistep syntactic planning to be implemented

3. Emotion is motivating, as just described. For example, fear learned by stimulusreinforcement association provides the motivation for actions performed to avoid noxious stimuli.

4. Communication. Monkeys, for example, may communicate their emotional state to others, by making an open-mouth threat to indicate the extent to which they are willing to compete for resources, and this may influence the behaviour of other animals. This aspect of emotion was emphasized by Darwin (1872), and has been studied more recently by Ekman $(1982,1993)$. He reviews evidence that humans can categorize facial expressions into the categories happy, sad, fearful, angry, surprised, and disgusted, and that this categorization may operate similarly in different cultures. As shown elsewhere, there are neural systems in the orbitofrontal cortex, amygdala, and overlying temporal cortical visual areas that are specialized for the face-related aspects of this processing (Rolls 2005b, 2007c; Rolls et al. 2006). 
5. Social bonding. Examples of this are the emotions associated with the attachment of the parents to their young, and the attachment of the young to their parents.

6. The current mood state can affect the cognitive evaluation of events or memories (see Oatley and Jenkins 1996). This may facilitate continuity in the interpretation of the reinforcing value of events in the environment. A hypothesis that back projections from parts of the brain involved in emotion such as the orbitofrontal cortex and amygdala implement this is described in Emotion Explained (Rolls 2005b).

7. Emotion may facilitate the storage of memories. One way this occurs is that episodic memory (i.e., one's memory of particular episodes) is facilitated by emotional states (Rolls 2005b, 2008b). A second way in which emotion may affect the storage of memories is that the current emotional state may be stored with episodic memories, providing a mechanism for the current emotional state to affect which memories are recalled. A third way that emotion may affect the storage of memories is by guiding the cerebral cortex in the representations of the world that are set up (Rolls 2008b).

8. Another function of emotion is that by enduring for minutes or longer after a reinforcing stimulus has occurred, emotion may help to produce persistent and continuing motivation and direction of behaviour, to help achieve a goal or goals.

9. Emotion may trigger the recall of memories stored in neocortical representations. Amygdala back projections to the cortex could perform this for emotion in a way analogous to that in which the hippocampus could implement the retrieval in the neocortex of recent (episodic) memories (Rolls 2008b; Rolls and Stringer 2001).

\section{Reward, punishment and emotion in brain design: an evolutionary approach}

The theory of the functions of emotion is further developed in Emotion Explained (Rolls 2005b). Some of the points made help to elaborate greatly on 3 above. Rolls (2005b) considers the fundamental question of why we and other animals are built to use rewards and punishers to guide or determine our behaviour. Why are we built to have emotions, as well as motivational states? Is there any reasonable alternative around which evolution could have built complex animals?

Rolls (2005b) argues that a role of natural selection is to guide animals to build sensory systems that will respond to dimensions of stimuli in the natural environment along which actions can lead to better ability to pass genes on to the next generation, that is to increased fitness. The animals must be built by such natural selection to make actions that will enable them to obtain more rewards, that is to work to obtain stimuli that will increase their fitness. Correspondingly, animals must be built to make responses that will enable them to escape from, or learn to avoid, stimuli that will reduce their fitness. There are likely to be many dimensions of environmental stimuli 
along which responses can alter fitness. Each of these dimensions may be a separate reward/punishment dimension. An example of one of these dimensions might be food reward. It increases fitness to be able to sense nutrient need, to have sensors that respond to the taste of food, and to perform behavioural responses to obtain such reward stimuli when in that need or motivational state. Similarly, another dimension is water reward, in which the taste of water becomes rewarding when there is body fluid depletion (see Chapter 6 of Emotion Explained).

With many reward/punishment dimensions for which actions may be performed (see Table 8.1 for a non-exhaustive list!), a selection mechanism for actions performed is needed. In this sense, rewards and punishers provide a common currency scale for inputs to response selection mechanisms. Evolution must set the magnitudes of each of the different reward systems so that each will be chosen for action in such a way as to maximize overall fitness. Food reward must be chosen as the aim for action if a nutrient is depleted; but water reward as a target for action must be selected if current water depletion poses a greater threat to fitness than the current food depletion. This indicates that each reward must be carefully calibrated by evolution to have the right value in the common currency for the competitive selection process. Other types of behaviour, such as sexual behaviour, must be selected sometimes, but probably less frequently, in order to maximize fitness (as measured by gene transmission into the next generation). Many processes contribute to increasing the chances that a wide set of different environmental rewards will be chosen over a period of time, including not only need-related satiety mechanisms which decrease the rewards within a dimension, but also sensory-specific satiety mechanisms, which facilitate switching to another reward stimulus (sometimes within and sometimes outside the same main dimension), and attraction to novel stimuli. Finding novel stimuli rewarding is one way that organisms are encouraged to explore the multidimensional space in which their genes are operating.

The implication of this comparison is that operation by animals using reward and punishment systems tuned to dimensions of the environment that increase fitness provides a mode of operation that can work in organisms that evolve by natural selection. It is clearly a natural outcome of Darwinian evolution to operate using reward and punishment systems tuned to fitness-related dimensions of the environment, if instrumental goal-directed actions are to be made by the animals, rather than just pre-programmed responses and movements such as tropisms and taxes. This view of brain design in terms of reward and punishment systems built by genes that gain their adaptive value by being tuned to a goal for action offers I believe a deep insight into how natural selection has shaped many brain systems, and is a fascinating outcome of Darwinian thought.

We thus have part of a theory of how value is placed on some stimuli. Value will be placed according to whether the stimuli activate our reward or punishment systems, themselves tuned during evolution to produce goals that will increase the fitness of our genes. Moreover, we have seen that these gene-defined goals may include a wide range 
of reinforcers, including many involved in social behaviour, and define some of the things that make people and objects attractive. Before building in the direction of aesthetics, we need to take into account a second way in which humans by reasoning can define a wider range of goals, or at least can place different value on goals as a result of reasoning. I now compare these two routes to action (see also Rolls 2003, 2005b).

\section{Dual routes to action: gene-defined goals, and syntactic reasoning}

The first route is via the brain systems that have been present in non-human primates such as monkeys, and to some extent in other mammals, for millions of years, and have built in the brain a system for defining these goals. Achieving these goals feels pleasant or unpleasant. The goals may be primary reinforcers, or stimuli associated with them by learning. This value assessment may be based on a number of different factors. One is the previous reinforcement history, which involves stimulus-reinforcement association learning, and its rapid updating especially in primates using the orbitofrontal cortex. A second is the current motivational state, for example whether hunger is present, whether other needs are satisfied, etc. A third factor that affects the computed reward value of the stimulus is whether that reward has been received recently. If it has been received recently but in small quantity, this may increase the reward value of the stimulus. This is known as incentive motivation or the 'salted-nut' phenomenon. The adaptive value of such a process is that this positive feedback of reward value in the early stages of working for a particular reward tends to lock the organism onto behaviour being performed for that reward. A fourth factor is the computed absolute value of the reward or punishment expected or being obtained from a stimulus, e.g., the sweetness of the stimulus (set by evolution so that sweet stimuli will tend to be rewarding, because they are generally associated with energy sources), or the pleasantness of touch (set by evolution to be pleasant according to the extent to which it brings animals of the opposite sex together, and depending on the investment in time that the partner is willing to put into making the touch pleasurable, a sign which indicates the commitment and value for the partner of the relationship). After the reward value of the stimulus has been assessed in these ways, behaviour is then initiated based on approach towards or withdrawal from the stimulus. A critical aspect of the behaviour produced by this type of system is that it is aimed directly towards obtaining a sensed or expected reward, by virtue of connections to brain systems such as the basal ganglia and cingulate cortex (Rolls 2009) which are concerned with the initiation of actions (see Fig. 8.2).

Now part of the way in which the behaviour is controlled with this first route is according to the reward value of the outcome. At the same time, the animal may only work for the reward if the cost is not too high. Part of the value of having the computation expressed in this reward-minus-cost (or 'net reward') form is that there 
is then a suitable 'currency', or net reward value, to enable the animal to select the behaviour with currently the most net reward gain (or minimal aversive outcome).

The second route in humans and perhaps closely related animals involves a computation with many 'if... then' statements, to implement a plan to obtain a reward. In this case, the reward may actually be deferred as part of the plan, which might involve working first to obtain one reward, and only then to work for a second more highly valued reward, if this was thought to be overall an optimal strategy in terms of resource usage (e.g., time). In this case, syntax is required, because the many symbols (e.g., names of people) that are part of the plan must be correctly linked or bound. Such linking might be of the form: 'if A does this, then B is likely to do this, and this will cause $\mathrm{C}$ to do this...' The requirement of syntax for this type of planning implies that an output to language systems in the brain is required for this type of planning (see Fig. 8.2). Thus the explicit language system in humans may allow working for deferred rewards by enabling use of a one-off, individual, plan appropriate for each situation.

The question then arises of how decisions are made in animals such as humans that have both the implicit, direct reward-based, and the explicit, rational, planning systems (see Fig. 8.2) (Rolls 2008b). One particular situation in which the first, implicit, system may be especially important is when rapid reactions to stimuli with reward or punishment value must be made, for then the direct connections from structures such as the orbitofrontal cortex to the basal ganglia may allow rapid actions (Rolls 2005b). Another is when there may be too many factors to be taken into account easily by the explicit, rational, planning, system, when the implicit system may be used to guide action. In contrast, when the implicit system continually makes errors, it would then be beneficial for the organism to switch from automatic, direct, action based on obtaining what the orbitofrontal cortex system decodes as being the most positively reinforcing choice currently available, to the explicit conscious control system which can evaluate with its long-term planning algorithms what action should be performed next. Indeed, it would be adaptive for the explicit system to regularly be assessing performance by the more automatic system, and to switch itself in to control behaviour quite frequently, as otherwise the adaptive value of having the explicit system would be less than optimal.

There may also be a flow of influence from the explicit, verbal system to the implicit system, in that the explicit system may decide on a plan of action or strategy, and exert an influence on the implicit system that will alter the reinforcement evaluations made by and the signals produced by the implicit system (Rolls 2005b).

The second route to action allows, by reasoning, decisions to be taken that might not be in the interests of the genes, might be longer-term decisions, and might be in the interests of the individual. An example might be a choice not to have children, but instead to devote oneself to science, medicine, music, or literature. The reasoning, rational, system presumably evolved because taking longer-term decisions involving planning rather than choosing a gene-defined goal might be advantageous at least sometimes for genes. But an 'unforeseen' consequence of the evolution of the rational system might be that the decisions would, sometimes, not be to the advantage of any 
genes in the organism. After all, evolution by natural selection operates utilizing genetic variation like a Blind Watchmaker (Dawkins 1986). In this sense, the interests when the second route to decision-making is used are at least sometimes those of the 'selfish phenotype'. (Indeed, we might euphonically say that the interests are those of the 'selfish phene' (where the etymology is Gk. phaino, 'appear', referring to appearance, hence the thing that one observes, the individual).

Hence the decision-making is between a first system where the goals are genedefined, and a second rational system in which the decisions may be made in the interests of the genes, or in the interests of the phenotype and not in the interests of the genes. Thus we may speak of the choice as sometimes being between the 'Selfish Genes' (Dawkins 1989) and the 'Selfish Phenes' (Rolls 2011, b, a).

Now what keeps the decision-making between the 'Selfish Genes' and the 'Selfish Phenes' more or less under control and in balance? If the second, rational, system chose too often for the interests of the 'Selfish Phene', the genes in that phenotype would not survive over generations. Having these two systems in the same individual will only be stable if their potency is approximately equal, so that sometimes decisions are made with the first route, and sometimes with the second route. If the two types of decisionmaking, then, compete with approximately equal potency, and sometimes one is chosen, and sometimes the other, then this is exactly the scenario in which stochastic processes in the decision-making mechanism are likely to play an important role in the decision that is taken. The same decision, even with the same evidence, may not be taken each time a decision is made, because of noise in the system, and this makes the decision-making probabilistic (Rolls and Deco 2010).

The system itself may have some properties that help to keep the system operating well. One is that if the second, rational, system tends to dominate the decision-making too much, the first, gene-based emotional system might fight back over generations of selection, and enhance the magnitude of the reward value specified by the genes, so that emotions might actually become stronger as a consequence of them having to compete in the interests of the selfish genes with the rational decision-making process.

Another property of the system may be that sometimes the rational system cannot gain all the evidence that would be needed to make a rational choice. Under these circumstances the rational system might fail to make a clear decision, and under these circumstances, basing a decision on the gene-specified emotions is an alternative. Indeed, Damasio (1994) argued that under circumstances such as this, emotions might take an important role in decision-making. In this respect, I agree with him, basing my reasons on the arguments above. He called the emotional feelings gut feelings, and, in contrast to me, hypothesized that actual feedback from the gut was involved. His argument seemed to be that if the decision was too complicated for the rational system, outputs are sent to the viscera, and whatever is sensed by what they send back could be used in the decision-making, and would account for the conscious feelings of the emotional states. My reading of the evidence is that the feedback from the periphery is not necessary for the emotional decision-making, or for the feelings, 
nor would it be computationally efficient to put the viscera in the loop given that the information starts from the brain, but that is a matter considered elsewhere (Maia and McClelland 2004; Rolls 2005b).

Another property is that the interests of the second, rational, system, although involving a different form of computation, should not be too far from those of the gene-defined emotional system, for the arrangement to be stable in evolution by natural selection. One way that this could be facilitated would be if the gene-based goals felt pleasant or unpleasant in the rational system, and in this way contributed to the operation of the second, rational, system. This is something that I propose is the case, as considered further in the next section.

The operation of the reasoning system-how its multistep plans may be corrected by higher order thoughts, and how this higher order thought process appears to be closely related to consciousness-is developed elsewhere (Rolls, 2003, 2004, 2005a, 2005b, 2007b, 2007d, 2008a). When I write here about aesthetic (and emotional) feelings, the conscious feelings I refer to are of the type considered in those sources.

\section{A theory of aesthetics}

\subsection{Introduction to and outline of the theory}

We thus have part of a theory of how value is placed on some stimuli. Value will be placed according to whether the stimuli activate our reward or punishment systems, themselves tuned during evolution to produce goals that will increase the fitness of our genes. Moreover, we have seen that these gene-defined goals may include a wide range of reinforcers, including many involved in social behaviour, and define some of the things that make people and objects attractive. We have seen that humans by reasoning can define a wider range of goals, or at least can place different values on goals as a result of reasoning, and use this as a second route to action. We have also seen that cognition can influence the representation of affective value in the orbitofrontal cortex. The analysis of the evolutionary basis of reward value provides a fundamental and Darwinian way to understand emotion (Rolls 2005b).

I now explore whether the same approach can provide a neurobiological basis for understanding aesthetics. Now that we have a fundamental, Darwinian, approach to the value of people, objects, relationships, etc., I propose that this provides a fundamental approach to understanding aesthetics. I propose that while the gene-specified rewards and punishers define many things that have aesthetic value, the value that we place on items is enhanced by the reasoning, rational, system, which enables what produces aesthetic value to become highly intellectualized, as in music. However, even here I argue that there are certain adaptive principles that influence the operation of our rational system that provide a systematic way to understand aesthetics.

I emphasize at the outset that this does not at all reduce aesthetics to a common denominator. Genetic variation is essential to evolution by natural selection, and this is 
one reason why we should expect different people to assign aesthetic value differently. But rational thought, which will lead in different directions in different people, partly because of noise caused by random neuronal firing times in the brain (Rolls and Deco 2010), and because of what they have learned from the environment, and because different brain areas will be emphasized in different people, will also be different between individuals, so that the rational system will also contribute to differences between individuals in what is considered aesthetic.

Indeed, although the theory presented here on the origin of aesthetics is a reductive explanation, in that it treats the underlying bases and causes, it should not be seen at all to 'reduce' aesthetics. Far from it. When we understand the underlying origins and bases of aesthetics, we see that the processes involved are elegant and beautiful, as part of a Darwinian theory. But the approach also provides important pointers about how to enhance aesthetics. For example, by understanding that verbal level cognitive factors that can be produced by reasoning have a top-down modulatory influence on the first cortical area where value (reward) is made explicit in the representation, the orbitofrontal cortex (De Araujo et al. 2005; Grabenhorst et al. 2008; McCabe et al. 2008), we can see ways in which we can enhance our aesthetic feelings. (For example, if love be the thing, then it can be heightened by explicitly choosing the musical treatment of it in Tristan and Isolde.)

I should also emphasize that aesthetic value judgements will usually be influenced by a number of different value factors, so that while accounting for an aesthetic judgement by just one of the value factors I describe is and will often seem too simple, it does seem that aesthetic value judgements can be understood by combinations of some of the factors I describe.

I also emphasize that this is a theory of the origin of aesthetics. I provide generic examples, but of course cannot cover all factors that influence value. An indication of the range of factors that can provide a basis for aesthetic judgements is shown in Table 8.1, but this is by no means complete. These examples are gene-defined goals for action, and we are built to want to obtain these goals (the basis for motivation), to treat them operationally as rewards or punishers, and to have pleasant or unpleasant affective feelings when they are delivered (the basis of emotion) (Rolls 2005b). It is argued here that these factors contribute to aesthetic judgements, that any one stimulus will often have multiple such attributes, and that these factors are afforced by operations of the reasoning system.

I emphasize that rewards, of which examples are provided in Table 8.1, contribute to what makes stimuli or brain processing positively aesthetic, beautiful; and that the punishers contribute to what makes stimuli or processing in the brain aesthetically negative, lacking beauty, ugly, or distasteful. Both rewards and punishers are needed for the theory of aesthetics.

The overall theory of the origin of aesthetics I propose is that natural selection, whether operating by 'survival or adaptation selection', or by sexual selection, operates by specifying goals for action, and these goals are aesthetically and subjectively 
attractive or beautiful (Rolls 2005a), or the opposite, and provide what I argue here is the origin of many judgements of what is aesthetic. Examples of these rewards and punishers, many of which operate for 'survival or adaptation selection', and many of which contribute to aesthetic experience, are shown in Table 8.1.

In contrast to my theory, Miller $(2000,2001)$ emphasizes the role of sexual selection. Understanding the mechanisms that drive evolution to make certain stimuli rewarding or punishing can help us to understand the origin of aesthetics, and I therefore summarize the characteristics of these two evolutionary processes in Sections 5.2 and 5.3.

I note first that the term 'natural selection' encompasses in its broad sense both 'survival or adaptation selection', and sexual selection. Both are processes now understood to be driven by the selection of genes, and it is gene competition and replication into the next generation that is the driving force of biological evolution (Dawkins 1986, 1989). The distinction can be made that with 'survival or adaptation selection', the genes being selected for make the individual stronger, healthier, and more likely to survive and reproduce; whereas sexual selection operates by sexual choice selecting for genes that may or may not have survival value to the individual, but enable the individual to be selected as a mate or to compete for a mate in intra-sexual selection, and thus pass on the genes selected by intra-sexual or inter-sexual selection to the offspring. More generally, we might have other types of selection as further types of natural selection, including selection for good parental care, and kin selection.

\section{2 'Survival' or 'adaptation' selection (natural selection in a narrow sense)}

Darwin (1871) distinguished natural selection from sexual selection, and this distinction has been consolidated and developed (Fisher 1930; Hamilton 1964; Zahavi 1975; Dawkins 1986; Grafen 1990a, 1990b; Dawkins 1995; Hamilton 1996; Miller 2000). Natural selection can be used in a narrow sense to refer to selection processes that lead to the development of characteristics that have a function of providing adaptive or survival value to an individual so that the individual can reproduce, and pass on its genes. In its narrow sense, natural selection can be thought of as 'survival or adaptation selection'. An example might be a gene or genes that specify that the sensory properties of food should be rewarding (and should taste pleasant) when we are in a physiological need state for food. Many of the reward and punishment systems described here and by Rolls (2005b) deal with this type of reward and punishment decoding that has evolved to enable genes to influence behaviour in directions in a high-dimensional space of rewards and punishments that are adaptive for survival and health of the individual, and thus promote reproductive success or fitness of the genes that build such adaptive functionality. We can include kin-related altruistic behaviours because the behaviour is adaptive in promoting the survival of kin, and thus promoting the likelihood that the kin (who contain one's genes, and are likely to share the genes for kin altruism) survive and reproduce. We can also include reciprocal altruism as an example of 'survival or adaptation' selection. Tribalism can be treated similarly, for it probably has its origins in 
altruism. Resources and wealth are also understood at least in part as being selected by natural selection, in that resources and wealth may enable the individual to survive better. As we will see next, resources and wealth can also be attractive as a result of sexual selection. (I note that natural selection in a broad sense includes 'survival or adaptation' selection, sexual selection, selection for good parental care, etc.)

\subsection{Sexual selection}

Darwin (1871) also recognized that evolution can occur by sexual selection, when what is being selected for is attractive to potential mates (inter-sexual selection), or helps in competing with others of the same sex (intra-sexual selection, e.g., the deer's large antlers, and a strong male physique). The most cited example of mate selection (intersexual selection) is the peacock's large tail, which does not have survival value for the peacock (and indeed it is somewhat of a handicap to have a very long tail), but, because it is attractive to the peahen, becomes prevalent in the population. Indeed, part of the reason for the long tail being attractive may be that it is an honest signal of phenotypic fitness (or 'fitness indicator'), in that having a very long tail is a handicap to survival (Zahavi 1975), though the signalling system that reveals this only operates correctly if certain conditions apply (Grafen 1990a, 1990b; Maynard Smith and Harper 2003). The inherited genes for a long tail may be expressed in the female's sons, and they will accordingly be attractive to females in the next generation. Although the female offspring of the mating will not express the male father's attractive long-tail genes, these genes are likely to be expressed in her sons. The female has to evolve to find the characteristic being selected for in males attractive for this situation to lead to selection of the characteristic being selected for by the choosiness of females. Indeed, the fact that the female who chose a long-tailed male has children following her mating with genes for liking long-tailed males, and for generating long tails, is part of what leads to the sexual selection. The fact that the long tail is actually a handicap for the peacock, and so is a signal of general physical fitness in the male, may be one way in which sexual selection can occur stably (Zahavi 1975; Grafen 1990a, 1990b).

The peacock tail example is categorized as sexual selection because the long tail is not adaptive to the individual with the long tail, though of course it is useful to the male's genes to have a long tail if females are choosing it because it indicates general physical fitness. However, sexual selection can also occur when a revealing or index signal or fitness indicator is not associated with a handicap, but is hard to fake, so that it is necessarily an honest fitness indicator (Maynard Smith and Harper 2003). An example occurs in birds that may show bare skin as part of their courtship, providing a sign that they are parasite resistant (Hamilton and Zuk 1982). Revealing bare skin in women can be beautiful and may have its origins partly in this, as well as in perhaps displaying secondary sexual characteristics (such as breasts) that may be attractive to men (with an origin as indicators of sexual maturity and of maternal readiness). (Note that this account is very different to that of Sigmund Freud.) 
The mechanisms of mate choice evolution include the following (Andersson and Simmons 2006):

(i) Direct phenotypic effects. Female preference for a male ornament can evolve as a result of direct phenotypic benefits if the ornament reflects the ability of the male to provide material advantages, such as high-quality territory, nutrition, parental care, or protection.

(ii) Sensory bias. Female preference favouring a male ornament can initially evolve under natural selection for other reasons, for instance in the context of foraging or predator avoidance. Males evolving traits that exploit this bias then become favoured by mate choice (Ryan 1998)

(iii) Fisherian sexy sons. If there are genetic components to variance in female preference and male trait, a female choosing a male with a large trait bears daughters and sons that can both carry alleles for a large trait, and for the preference for it. This genetic coupling might lead to self-reinforcing co-evolution between trait and preference (Fisher 1930; Mead and Arnold 2004). (Sexual election may be identified when females choose sexy mates so that the female's sons will be sexy and attractive. Survival selection may be identified if the choice helps the female's daughters as well as sons.)

(iv) Fitness indicator mechanisms ('good genes' or 'handicap mechanisms') suggest that attractive male traits reflect broad genetic quality (Zahavi 1975; Grafen 1990a, 1990b). Female preference for such traits can provide genetic benefits to those of her offspring that inherit favourable alleles from their father.

(v) Genetic compatibility mechanisms. As well as additive genetic benefits reflected by indicator traits, there might be non-additive benefits from choosing a mate with alleles that complement the genome of the chooser. Examples have been found for instance in major histocompatibility complex (MHC) genes, which may be associated with odour preferences for potential mates (Dulac and Torello 2003). These genes are involved in the process by which a cell infected with an antigen (from a virus or bacterium) displays short peptide sequences of it at the cell surface, and the T lymphocytes of the immune system then recognize the fragment, and build an antibody to it. This MHC gene system must maintain great diversity to help detect uncommon antigens, with an advantage arising from mating with an individual with different MHC genes. At least some of the MHC genes are very closely associated with gene-specified pheromone receptors, with individual pheromone receptor cells often expressing one or a few MHC genes in a complex with specific V2R-specified receptors (Dulac and Torello 2003). Thus, a mate may be found attractive (and beautiful) based on odour, and a mechanism such as this may operate in humans (see Rolls 2005b).

The evolution of mate choice is based either on direct selection of a preference that gives a fitness advantage (mechanisms i-ii) (i.e., there is a survival or adaptation advantage); or on indirect selection of a preference as it becomes genetically correlated 
with directly selected traits (mechanisms iii, iv) (i.e., the trait has no advantage, and might be thought of as a useless ornament) (Andersson 1994; Mead and Arnold 2004). In addition, rather than favouring any particular display trait, mate choice might evolve because it conveys non-additive genetic benefits (mechanism v). These mechanisms are mutually compatible and can occur together, rendering the evolution of mating preferences a multiple-causation problem, and calling for estimation of the relative roles of individual mechanisms (Andersson, 1994). ${ }^{1}$

Some characteristics of sexual selection that help to separate it from survival selection are as follows:

First, the sexually selected characteristic is usually sexually dimorphic, with the male typically showing the characteristic. (For example the peacock but not the peahen has the long tail.) This occurs because it is the female who is being choosy, and is selecting males. The female is the choosy one because she has a considerable investment in her offspring, whom she may need to nurture until birth, and then rear until independent, and for this reason has a much more limited reproductive potential than the male, who could in principle father large numbers of offspring to optimize his genetic potential. This is an example of a sexual dimorphism selected by inter-sexual selection. An example of a sexual dimorphism selected by intra-sexual selection is the deer's antlers. Sexual dimorphism usually reflects sexual selection, but may not, with an example being that the female may be cryptic (hidden against the background, camouflaged) when incubating eggs, in order to be a good parent.

Second, sexually selected characteristics such as ornamentation helpful in identification are typically species-specific, whereas naturally selected characteristics may, because they have survival value for individuals, be found in many species within a genus, and even across genera.

Third, and accordingly, the competition is within a species for sexual selection, whereas competition may be across as well as within species for natural (survival) selection.

Fourth, sexual selection operates most efficiently in polygynous species, that is species where some (attractive) males must mate with two or more females, and unattractive males must be more likely to be childless. Polygyny does seem to have been present to at least some extent in our ancestors, as shown for example by body size differences, with males larger than females. This situation is selected because males compete harder with each other in polygynous species compared to monogamous, where there is less competition. In humans, the male is 10 per cent taller, 20 per cent

\footnotetext{
${ }^{1}$ I note that even in the Fisherian case, iii, for 'runaway' to occur there must be a critical proportion of females in the population with the preference, and this is only likely to occur if the ornamental characteristic has some survival value. For example, a slightly longer tail may have helped flying, even if that characteristic later showed runaway. Further, runaway can refer to the characteristic, or to the proportion of individuals (males) with the characteristic. Overall, the implication is that there may be some 'use' or survival value even in characteristics that later become sexually selected by a Fisherian process. Further, I note that runaway may occur with a Fisherian process, but not with a handicap, which is self-limiting.
} 
heavier, 50 per cent stronger in the upper body muscles, and 100 per cent stronger in the hand grip strength than the average female (Miller 2000).

Fifth, the sexually selected characteristics are often apparent after but not before puberty. In humans, one possible example is the deep male voice.

Sixth, there may be marked differences between individuals, as it is these differences that are being used for mate choice. Sexual selection thus promotes genetic diversity. In contrast, when natural or survival selection is operating efficiently, there may be little variation between individuals.

Seventh, the fitness indicator may be costly or difficult to produce, as in this way it can reflect real fitness, and be kept honest (mechanism iv above).

However, sexual selection is not as pure as was once thought: females are less choosy, and more promiscuous, than was once thought (Birkhead 2000).

Overall, Darwinian natural or survival selection increases health, strength, and potentially resources, and survival of the individual, and thus ability to mate and reproduce, and to look handsome or beautiful. Inter-sexual sexual selection does not make the individual healthier, but does make the individual more attractive as a mate, as in female choice, an example of inter-sexual selection. Intra-sexual sexual selection does not necessarily help survival of the individual, but does help in competition for a mate, for example in intimidation of one male by another (Darwin 1871; Kappeler and van Schaik 2004). The behaviours and characteristics involved in sperm competition, which itself may influence what is judged to be attractive and beautiful, are produced by intrasexual sexual selection (Rolls 2005b; Andersson and Simmons 2006).

It turns out that many of the best examples of inter-sexual sexual selection are in birds (for example the peacock's tail, and the male lyre bird's tail). In mammals, including primates, the selection is often by size, strength, physical prowess, and aggressiveness, which provide for direct physical (and other types of) competition, and are examples of intra-sexual selection (in males) (Kappeler and van Schaik 2004).

It has been suggested that sexual selection is important for further types of characteristic in humans. For example, it has been suggested that human mental abilities that may be important in courtship such as kindness, humour, and telling stories, are the type of characteristic that may be sexually selected in humans (Miller 2000). Before assessing this (in Section 5.8), and illuminating thus some of what may be sexually selected rewards and punishers that therefore contribute to human affective states and aesthetics, we should note a twist in how sexual selection may operate in humans.

In humans, because babies are born relatively immature and may take years of demanding care before they can look after themselves, there is some advantage to male genes of providing at least some parental care for the children. That is, the father may invest in his offspring. In this situation, where there is a male investment, the male may optimize the chance of his genes faring well by being choosy about his wife. The implication is that in humans, sexual selection may be of female characteristics (by males), as well as of male characteristics (by females). This may mean that the differences between the sexes may not be as large as can often be the case with inter-sexual 
sexual selection, where the female is the main chooser. One example of how sexual selection may affect female characteristics is in the selection for large breasts. These may be selected to be larger in humans than is really necessary for milk production, by the incorporation of additional fat. This characteristic may be attractive to males (and hence produce affective responses in males) because it is a symbol relating to fertility and child rearing potential, and not because large breasts have any particular adaptive value. It has even been suggested that the large breast size makes them useful to males as a sign of reproductive potential, for their pertness is maximal when a (young) woman's fertility and reproductive potential is at its highest. Although large breasts may be less pert with age, and it might thus be thought to be an advantage for women not to have large breasts, it may be possible that this is offset by the advantageous signal of a pert but large breast when fertility and reproductive potential is at its maximal when young, as this may attract high status males (even though there may be disadvantages later) (Miller 2000). Thus it is possible that inter-sexual selection contributes to the large breast size of some women. The fact that the variation is quite large is consistent with this being a sexually selected, not survival-selected, characteristic. Thus sexual selection of characteristics may occur in women as well as in men, and may contribute to aesthetic judgements.

\subsection{Beauty in men and women}

Given this background in the processes that drive evolution to make certain stimuli and types of brain processing rewarding or punishing, in this section I examine how they contribute to what factors make men and women aesthetically beautiful.

What factors are decoded by our brains to influence the attractiveness and beauty (reward value) of men and women? This can affect their selection as possible mates, and the factors are not necessarily the same for selection of a long-term vs. short-term partner (Rolls 2005b). I note that many of these factors may operate unconsciously, and that we may confabulate a rational verbal account about why we judge that something is beautiful. We may not realize that the following factors can influence our aesthetic judgements.

5.4.1 Female preferences: factors that make men attractive Factors that across a range of species influence female selection of male mates include the following:

Athleticism. The ability to compete well in mate selection (including being healthy and strong), as this will be useful for her genes when present in her male offspring. Athleticism may be attractive (rewarding) also as an indicator of protection from male marauding (single females are at risk in some species of abuse, and forced copulation, which circumvents female mate choice), from predators, and as an indicator of hunting competency (meat was important in human evolution, although the hunt may also have been co-opted by sexual selection as a mating ritual giving the males a chance to show off). Consistent with these points, women show a strong preference for tall, strong, athletic men (Buss and Schmitt 1993). 
Resources, power and wealth. In species with shared parental investment (which include many birds and humans), having power and wealth may be attractive to the female, because they are indicators of resources that may be provided for her young. Women should desire a man who shows willingness to invest resources (which should be defensible, accruable, and controllable) in his partner. (An expensive diamond engagement ring taken by a woman and kept guarded close to her on a finger meets these criteria. At the same time, the ring is a signal to her partner and to others that she is committed, which itself is attractive to her partner.) Women place a greater premium on income or financial prospects than men (Buss 1989). Further, in a cross-cultural study of 37 cultures with 10,047 participants, it was found that irrespective of cultural/ political/social background, women consistently placed more value on financial resources (100 per cent more) than men (Buss 1989, 1999). Women value a man's love as an indicator of resource commitment.

Status. Both now and historically, status hierarchies are found in many cultures (and species, for example monkeys' dominance hierarchies, and chickens' pecking order). Status correlates with the control of resources (e.g., alpha male chimpanzees take precedence in feeding), and therefore acts as a good cue for women. Women should therefore find men of high status attractive (e.g., rock stars, politicians, and tribal rulers), and these men should be able to attract the most attractive partners. Consistent with this, cross-culturally women regard high social status as more valuable than do men; and attractive women marry men of high status (Buss 1989, 1999). Status may be attractive because of direct effects (e.g., as an indicator of resources for children), or because of indirect effects (because high status implies good genes for offspring).

Age. Status and higher income are generally only achieved with age, and therefore women should generally find older men attractive. Cross-culturally women prefer older men (3.42 years older on average; and marriage records from 27 countries show that the average age difference was 2.99 years) (Buss 1989).

Ambition and industriousness, which may be good predictors of future occupational status and income, are attractive. Valued characteristics include those that show a male will work to improve their lot in terms of resources or in terms of rising up in social status. Cross-culturally, women rated ambition/industriousness as highly desirable (Buss 1989).

Testosterone-dependent features may also be attractive. These features include a strong (longer and broader) jaw, a broad chin, strong cheekbones, defined eyebrow ridges, a forward central face, and a lengthened lower face (secondary sexual characteristics that are a result of pubertal hormone levels). High testosterone levels are immuno-suppressing, so these features may be indicators of immuno-competence (and thus honest indicators of fitness). The attractiveness of these masculinized features increases with increased risk of conception across the menstrual cycle (Penton-Voak et al. 1999). The implication is that the neural mechanism controlling perception of attractiveness must be sensitive to oestrogen/progesterone levels in women. 
Another feature thought to depend on prenatal testosterone levels is the 2nd/4th digit ratio. A low ratio reflects a testosterone-rich uterine environment. It has been found that low ratios correlate with female ratings of male dominance and masculinity, although the relationship to attractiveness ratings was less clear (Swaddle and Reierson 2002).

Symmetry (in both males and females) may be attractive, in that it may reflect good development in utero, a non-harmful birth, adequate nutrition, and lack of disease and parasitic infections (Thornhill and Gangestad 1999). Fluctuating asymmetry (FA) reflects the degree to which individuals deviate from perfect symmetry on bilateral features (e.g., in humans, both ears, both feet, both hands and arms; in other species, bilateral fins, bilateral tail feathers). Greater asymmetry may reflect deviations in developmental design resulting from the disruptive effects of environmental or genetic abnormalities, and in some species is associated with lower fecundity, slower growth, and poorer survival. A low fluctuating asymmetry may thus be a sign of reproductive fitness (Gangestad and Simpson 2000). In humans, more symmetrical men reported more lifetime partners $(r=0.38)$, and more extra-pair partners; and women's choice of extra-pair partners was predicted by male symmetry (Gangestad and Simpson 2000). Moreover, women rate men as more attractive if they have high symmetry (low FA). Intellectual ability (which may be attractive to women) is also correlated with symmetry (Gangestad and Thornhill 1999).

Dependability and faithfulness may be attractive, particularly where there is paternal investment in bringing up the young, as these characteristics may indicate stability of resources (Buss 1999). Emotionally unstable men may also inflict costs on women, and thus women rate emotional stability and maturity as important. For example, jealousy might lead to abuse.

Risk-taking by men may be attractive to women, perhaps because it is a form of competitive advertising: surviving the risk may be an honest indicator of high quality genes (Barrett et al. 2002).

Characteristics that may not be adaptive in terms of the survival of the male, but that may be attractive because of inter-sexual sexual selection, are common in birds, perhaps less common in most mammals, though present in some primates (Kappeler and van Schaik 2004), and may be present in humans (see Section 5.3). An example of a sexually selected characteristic that may not increase the survival of the individual, but that may be attractive to females and thus increase the fitness of the male in terms of whether his genes are passed on to the next generation by reproduction, is the peacock's tail. These characteristics may in some cases be an honest indicator of health, in the sense that having a large gaudy tail may be a handicap.

Odour. The preference by women for the odour of symmetrical men is correlated with the probability of fertility of women as influenced by their cycle (Gangestad and Simpson 2000). Another way in which odour can influence preference is by pheromones that are related to MHC genes, which may provide a molecular mechanism for 
producing genetic diversity by influencing those who are considered attractive as mates, as described in Section 5.3.

It is important to note that physical factors such as high symmetry and that are indicators of genetic fitness may be especially attractive when women choose shortterm partners, and that factors such as resources and faithfulness may be especially important when women choose long-term partners, in what may be termed a conditional mating strategy (Buss 1999, 2006). This conditionality means that the particular factors that influence preferences alter dynamically, and preferences will often depend on the prevailing circumstances, including the current opportunities and costs.

5.4.2 Male preferences: what makes women attractive and beautiful to men Males are not always indiscriminate. ${ }^{2}$ When a male chooses to invest (for example to produce offspring), there are preferences for the partner with whom he will make the investment. Accurate evaluation of female quality (reproductive value) is therefore important, and a male will need to look out for cues to this, and find these cues attractive, beautiful, and rewarding. The factors that influence attractiveness include the following (see also Barrett et al. 2002):

Youth. As fertility and reproductive value in females is linked to age (reproductive value is higher when younger, and actual fertility in humans peaks in the twenties), males (unlike females) place a special premium on youth. It is not youth per se that men find attractive, but indicators of youth, for example neotenous traits such as blonde hair and wide eyes. An example of this preference is that male college students preferred an age difference on average of 2.5 years younger (Buss 1989). Another indicator of youth might be a small body frame, and it is interesting that this might contribute to the small body frame of some women in this example of sexual dimorphism.

Beautiful features. Features that are most commonly described as the most attractive tend to be those that are oestrogen-dependent, e.g., full lips and cheeks, and short lower facial features. (Oestrogen caps the growth of certain facial bones.) Like testosterone, oestrogen also affects the immune system, and its effects might be seen as 'honest indicators' of genetic fitness.

For example, when subjects were able to evolve a computer generated image into their ideal standard of female beauty, the beautiful composite had a relatively short lower face, small mouth, and full lips (Johnston and Franklin 1993).

There is some agreement across cultures about what constitute beautiful features. For example, in meta-analyses of 11 studies, it has been demonstrated that (a) raters agree about who is and is not attractive, both within and across cultures; (b) attractive children and adults are judged and treated more positively than unattractive children and adults, even by those who know them; and (c) attractive children and adults exhibit more positive behaviours and traits than unattractive children and adults (Langlois et al.

\footnotetext{
2 In fact, males are probably rarely indiscriminate, in that producing sperm and performing sexual behaviour do have costs (Pizzari et al. 2003), including, for example, the risk of catching disease.
} 
2000). In an fMRI study, it was found that attractive faces produce more activation of the human medial orbitofrontal cortex (where many pleasant stimuli are represented (Rolls and Grabenhorst 2008)) than unattractive faces (O'Doherty et al. 2003).

Further, small babies were even shown to gaze for longer at slides of the more attractive woman when shown pairs of pictures of women that differed in attractiveness (Langlois et al. 1987, 1991). In another study, 12-month-olds interacted with a stranger. The infants showed more positive affective tone, less withdrawal, and more play involvement with a stranger who wore a professionally constructed attractive than unattractive mask; and played longer with an attractive than an unattractive doll (Langlois et al. 1990). These results extend and amplify earlier findings showing that young infants exhibit visual preferences for attractive over unattractive faces. Both visual and behavioural preferences for attractiveness are evidently exhibited rather early in life.

Women appear to spend more time on fashion and enhancing beauty than men. Why should this be, when in most mammals it is males who may be gaudy to help in their competition for females, given that females make the larger investment in offspring? In humans, there is of course value to investment by males in their offspring, so women may benefit by attracting a male who will invest time and resources in bring up children together. But nevertheless, women do seem to invest more in bearing and then raising children, so why is the imbalance so marked, with women apparently competing by paying attention to their own beauty and fashion? Perhaps the answer is that males who are willing to make major investments of time and resources in raising the children of a partner are a somewhat limiting resource (as other factors may make it advantageous genetically for men not to invest all their resources in one partner), and because women are competing to obtain and maintain this scarce resource, being beautiful and fashionable is important to women. Faithful men may be a limited resource because there are alternative strategies that may have a low cost, whereas women are essentially committed to a considerable investment in their offspring. These factors lead to greater variability in men's strategies, and thus contribute to making men who invest in their offspring a more limited resource than women who invest in their offspring.

Given that men are a scare resource, and that women have such a major investment in their offspring that they must be sure of a man's commitment to invest before they commit in any way, we have a scientific basis for understanding why women are reserved and more cautious and shy in their interactions with men, which has been noticed to be prevalent in visual art, in which men look at women, but less vice versa (Berger 1972).

Body fat. The face is not the only cue to a woman's reproductive capacity, and her attractiveness, and beauty. Although the ideal body weight varies significantly with culture (in cultures with scarcity, obesity is attractive, and relates to status, a trend evident in beautiful painting throughout its history), the ideal distribution of body fat seems to be a universal standard, as measured by the waist-to-hip ratio (which cancels 
out effects of actual body weight). Consistently, across cultures, men preferred an average ratio of 0.7 (small waist/bigger hips) when rating female figures (line drawings and photographic images) for attractiveness (Singh and Luis 1995). Thornhill and Grammer (1999) also found high correlations between rating of attractiveness of nude females by men of different ethnicity. At a simpler level, a low waist-to-hip ratio is an indication that a woman is not already pregnant, and is thus a contributor to attractiveness and beauty.

Fidelity. The desire for fidelity in females is most obviously related to her concealed ovulation (see next paragraph and Rolls 2005b), and therefore the degree of paternity uncertainty that males may suffer. Males therefore place a premium on a woman's sexual history. Virginity was a requisite for marriage both historically (before the arrival of contraceptives) and cross-culturally (in non-Westernized societies where virginity is still highly valued) (Buss 1989). Nowadays, female monogamy in previous relationships is a sought-after characteristic in future long-term partners (Buss and Schmitt 1993). (Presumably with simple genetic methods now available for identifying the father of a child, the rational thought system (Rolls 2005b) might place less value on fidelity with respect to paternity issues as paternity can be established genetically, yet the implicit emotional system may still place high value on fidelity, as during evolution, fidelity was valued as an indicator of paternity probability.) The modern rational emphasis might be especially placed on valuing fidelity because this may indicate less risk of sexually transmitted disease, and perhaps the emotional value and attractiveness of fidelity will be a help in this respect.

Attractiveness and the time of ovulation. Although ovulation in some primates and in humans is concealed, ${ }^{3}$ it would be at a premium for men to pick up other cues to ovulation, and find women highly desirable (and beautiful) at these times. Possible cues include an increased body temperature reflected in the warm glow of vascularized skin (Vandenberghe and Frost 1986), and pheromonal cues. Indeed, male raters judged the odours of T-shirts worn during the follicular phase as more pleasant and sexy than odours from T-shirts worn during the luteal phase (Singh and Bronstad 2001). Women generally do not know when they are ovulating (and in this sense ovulation may be double blind), but there is a possibility that ovulation could unconsciously affect female behaviour. In fact, Event-Related Potentials (ERPs) were found to be greater to sexual stimuli in ovulating women, and these could reflect increased affective processing of the stimuli (Krug et al. 2000). This in turn might affect outward behaviour of the female, helping her to attract a mate at this time. Another possibly unconscious influence might be on the use of cosmetics and the types of clothes worn, which may be different close to the time of ovulation.

In most species, females invest heavily in the offspring in terms of providing the eggs and providing the care (from gestation until weaning, and far beyond weaning in the

\footnotetext{
${ }^{3}$ Perhaps so that males may be uncertain who the father is of a baby, and thus not threaten infanticide (Rolls 2005b).
} 
case of humans). Females are therefore a 'limited resource' for males allowing the females to be the choosier sex during mate choice. In humans, male investment in caring for the offspring means that male choice has a strong effect on intrasexual selection in women. Female cosmetic use and designer clothing could be seen as weapons in this competition, and perhaps are reflected in extreme female selfgrooming behaviour such as cosmetic surgery, or pathological disorders such as anorexia, bulimia, and body dysmorphic disorder. The modern media, by bombarding people with images of beautiful women, may heighten intra-sexual selection even further, pushing women's competitive mating mechanisms to a major scale.

\subsection{Pair-bonding, love, and beauty}

I extend in the next few sections the background provided in Sections 5.2 and 5.3 in the processes that drive evolution to make certain stimuli and types of brain processing rewarding or punishing, to other stimuli, events, and types of brain processing that produce aesthetic judgements.

Attachment to a particular partner by pair-bonding in a monogamous relationship, which in humans becomes manifest in love between pair-bonded parents, and which occurs in humans in relation to the advantage to the man of investing in his offspring, may have special mechanisms to facilitate it. Species in which attachment has been investigated include the prairie vole. In monogamous species of prairie voles, mating can increase pair-bonding (as measured by partner preference). Oxytocin, a hormone released from the posterior pituitary, whose other actions include the milk let-down response, is released during mating (Lee et al. 2009). Exogenous administration of oxytocin facilitates pair-bonding in both female and male prairie voles (Carter 1998). In female prairie voles, antagonists of oxytocin interfere with partner preference formation. In female prairie voles, the endogenous release of oxytocin is thus important in partner preference and attachment. Thus oxytocin has been thought of as the 'hormone of love'. Oxytocin gene knock-out mice fail to recognize familiar conspecifics after repeated social exposures, and injection of oxytocin in the medial amygdala restores social recognition (Winslow and Insel 2004). In males, the effects of oxytocin are facilitated by vasopressin, another posterior pituitary hormone whose other effects include promoting the retention of water by the kidney. In the case of vasopressin, it has been possible to show that the vasopressin $\mathrm{V} 1 \mathrm{a}$ receptor $(\mathrm{V} 1 \mathrm{aR})$ is expressed in higher concentration in the ventral forebrain of monogamous prairie voles than in promiscuous (i.e., polygamous) meadow voles, and that viral vector $\mathrm{V} 1 \mathrm{aR}$ transfer into the forebrain of the meadow mouse increases its partner preference (i.e., makes it more like a monogamous prairie vole) (Lim et al. 2004; Young 2008). Thus a single gene may be important in influencing monogamy vs. promiscuity in voles. Stress, or the administration of the hormone corticosterone which is released during stress, can facilitate the onset of new pair bonds (Devries et al. 1996).

Are similar mechanisms at work in humans to promote pair-bonding and love? There is as yet no definitive evidence, but in humans, oxytocin is released by 
intercourse, and especially at the time of orgasm, in both women and men (Meston and Frohlich 2000; Kruger et al. 2003). It has also been reported that women desiring to become pregnant are more likely to have an orgasm after their partner ejaculates (Singh et al. 1998).

An implication is that there may be hormonal, and other biological, mechanisms that promote a bifurcation in a state space (Rolls and Deco 2010), and have an effect of cementing attraction and love of a particular person after the process has been started. This may have an effect on (partly!) blinding a person to a partner's imperfections, and may thus contribute to each individual's judgements about the beauty of a partner, an aesthetic judgement.

Given this Darwinian approach rooted in selfish genes (Dawkins 1989), should we describe the aesthetic state of love as selfish? I suggest that the answer is that although individual acts can be truly altruistic (and non-adaptive), even the altruism implied by love must have its origins in selfish genes, which shape human behaviour to in this case produce a state that promotes the production of and survival of offspring. Overall, for a characteristic (such as falling in love, or reciprocal altruism, or kin altruism) that is influenced by genes to remain in a breeding population, the characteristic must be good for the (selfish) gene or it would be selected out. Even love guided by rational thought must not overall detract too much over generations from the wish to produce offspring, or it would tend (other things being equal) to be selected out of the gene population.

\subsection{Parental attachment: beautiful children}

Many mammal females make strong attachments to their own offspring, and this is also facilitated in many species by oxytocin. One model is the sheep, in which vaginalcervical stimulation and suckling, which release both oxytocin and endogenous opioids, facilitate maternal bonding (Keverne et al. 1997). Oxytocin injections can cause ewes to become attached to an unfamiliar lamb presented at the time oxytocin is released or injected, and oxytocin antagonists can block filial bonding in sheep. Perhaps oxytocin had an initial role in evolution in the milk let-down reflex, and then became appropriate as a hormone that might facilitate mother-infant attachment.

In humans the evidence is much more correlative, but oxytocin release during natural childbirth, and rapid placing of the baby to breast feed and release more oxytocin (Uvnas-moberg 1998), might facilitate maternal attachment to her baby. Prolactin, the female hormone that promotes milk production, may also influence maternal attachment - and how beautiful a mother thinks her child is. It is certainly a major factor in humans that bonding can change quite suddenly at the time that a child is born, with women having a strong tendency to shift their interests markedly towards the baby as soon as it is born (probably in part under hormonal influences), and this can result in relatively less attachment behaviour to the man. In men, oxytocin may also be involved in paternal behaviour (Wynne-Edwards 2001). 
Another aspect of parental care is that there is competition between the mother and child, for example over weaning (Trivers 1974). The mother may wish to devote resources to preparing for her next offspring (by building herself up); and continuing to breast feed delays the onset of fertility and cycling. In contrast, it is to the offspring's genetic advantage to demand milk and attention. The infant's scream can be seen as part of trying to wring resources out of its mother, potentially to an extent that is unfavourable for the mother's genes (Buss 1999).

As described above, females generally have a greater investment in their offspring, and tend to provide more parental care and perhaps become more attached than fathers. This situation is not as extreme in humans as in most other mammals, because human offspring are born relatively immature, and a father who helps to rear the offspring can help to increase the reproductive fitness of his genes.

Lack of parental care in stepfathers is evident in many species, and can be as extreme as the infanticide by a male lion of the pups of another father, so that his new female may come into heat more quickly to have babies by him (Bertram 1975). Infanticide also occurs in non-human primates (Kappeler and van Schaik 2004). In humans, the statistics indicate that stepfathers are much more likely to harm or kill children in the family than are real fathers (Daly and Wilson 1988).

The tendency to find babies beautiful is not of course restricted to parents of their own children. Part of the reason for this is that in the societies in which our genes evolved with relatively small groups, babies encountered might often be genetically related, and the tendency to find babies beautiful is probably a way to increase the success of selfish genes. One may still make these aesthetic judgements of babies in distant countries with no close genetic relationship, but this does not of course mean that such judgements do not have their evolutionary origin in kin-related advantageous behaviour.

\subsection{Synthesis on beauty in humans}

We see that many factors are involved in making humans attractive, and beautiful. All may contribute, to different extents, and differently in different individuals, and moreover we may not be conscious of some of the origins of our aesthetic judgements, but may confabulate reasons for what we judge to be aesthetic.

When there is a biological foundation for art, for example when it is figurative, and especially when it is about human figures, there may be a basis for consensus about what is good art - art that stimulates our rational system, and at the same time speaks to what we find beautiful due to our evolutionary history. However, if art becomes totally abstract, we lack the biological foundation for judging whether it is aesthetically beautiful, and judgements may be much more arbitrary, and driven by short-term fashion. Some abstraction away from very realistic and figurative in art can of course have advantages for it allows the viewer to create in their own experience of a work of art by adding their own interpretation. 
There is an important point here about the separation between art and the world. Objects of art can idealize beauty, and enhance it. An example is the emphasis on thin bodies, long limbs, and athletic poses found in some Art Deco sculpture, for example in the works of Lorenzl. Here what is beautiful can be made super-normal, one might say in the literal sense super-natural. Another example is in the emotion in the music of Tristan and Isolde. We see that art can emphasize and thus idealize some of the properties of the real world, and lose other details that do not enhance, or distract. This abstraction of what we find beautiful due to evolution can be seen in some semifigurative/semi-abstract art, as in some of the line drawings of humans by Matisse and Picasso. It is also found in the sculptures of human forms of Brancusi. What I argue is that if art goes too abstract, then it loses the aesthetic value that can be contributed by tapping into these evolutionary origins. Interesting cases are found in the sculptures of Barbara Hepworth and Henry Moore. In the case of Barbara Hepworth, I now see that she often retains sufficient figurative contribution to her sculpture to tap into evolutionary origins, and I show Fig. 8.3 as an example of a work that after all seems to have some relation to a male and female. Much of the sculpture of Henry Moore is clearly figurative, and where it becomes apparently very abstract it may lose what is gained by tapping into evolutionary origins, but may gain by association and interpretation in relation to his more figurative work. Where art becomes very abstract, as in some of the work of Mark Rothko, perhaps those especially interested are those who have expertise themselves in what is being achieved technically, such as the painting of colours by Rothko.

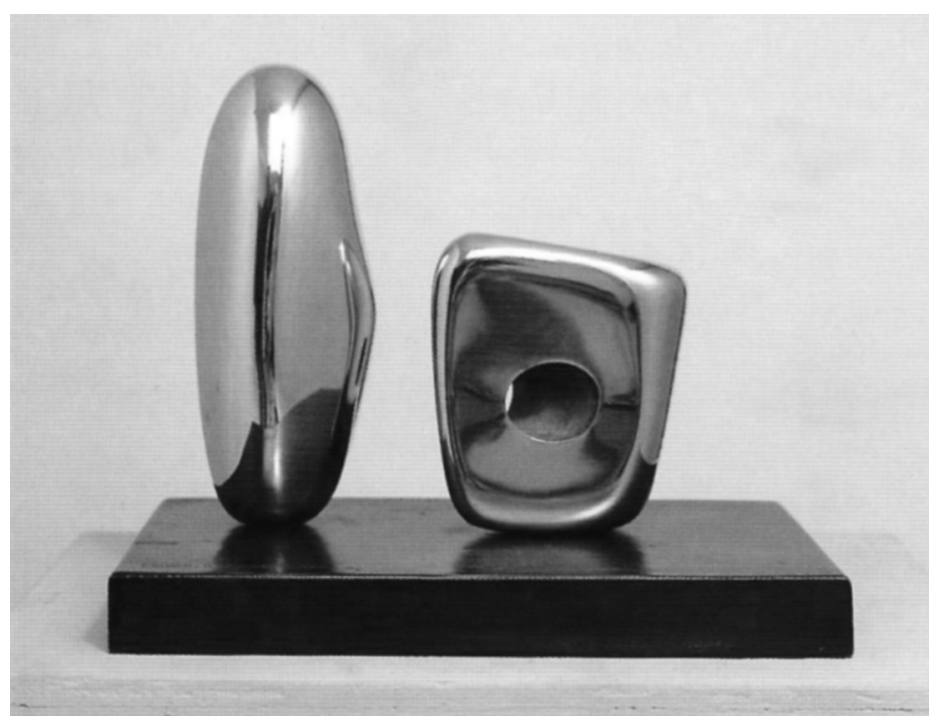

Figure 8.3 Two Forms (January) 1967. Barbara Hepworth 


\subsection{Sexual selection of mental ability, survival or adaptation selection of mental ability, and the origin of aesthetics}

Miller $(2000,2001)$ has developed the hypothesis that courtship provides an opportunity for sexual selection to select non-sexual mental characteristics such as kindness, humour, the ability to tell stories, creativity, art, and even language. He postulates that these are 'courtship tools, evolved to attract and entertain sexual partners'. One mechanism of sexual selection (see Section 5.3) views organisms as advertisers of their phenotypic fitness, and Miller sees these characteristics as such signals. From this perspective, hunting is seen as a costly and inefficient exercise (in comparison with food gathering) undertaken by men to obtain small gifts of meat for women, but at the same time to show how competitive and fit the successful hunter is in relation to other men. Conspicuous waste, and conspicuous consumption, are often signs in nature that sexual selection is at work, with high costs for behaviours that seem maladaptive in terms of survival and natural selection in the narrow sense. The mental characteristics described above are not only costly in terms of time, but may rely on many genes operating efficiently for these characteristics to be expressed well, and so, Miller suggests, may be 'fitness indicators'. Consistent with sexual selection, there is also great individual variability in these characteristics, providing a basis for choice.

One mental characteristic that Miller suggests could have evolved in this way is kindness, which is very highly valued by both sexes (Buss 1999), and is usually judged as aesthetically pleasing. In human evolution, being kind to the mother's children may have been seen as an attractive characteristic in men during courtship, especially when relationships may not have lasted for many years, and the children might not be those of the courting male. Kindness may also be used as an indicator of future cooperation. In a sense kindness thus may indicate potential useful benefits, consistent with the fact that across cultures human females tend to prefer males who have high social status, good income, ambition, intelligence, and energy (Buss 1999). Kindness may also be related to kin altruism (Hamilton 1964) or to reciprocal altruism (Trivers 1971), both of which are genetically adaptive strategies.

Although the simple interpretation of all these mental characteristics is that they indicate a good provider and potential material and genetic benefits (and thus would be subject to natural or survival selection), Miller (2000) argues that at least kindness is being used in addition as a fitness indicator and is being sexually selected.

Morality can be related in part to kin and reciprocal altruism, which influence survival, and make many of the behaviours described as moral also attractive, because of their evolutionary adaptive value (Ridley 1996; Rolls 2005b). In addition, moral behaviour may bring reproductive benefits and be attractive through the social status that it inspires or by direct mate choice for moralistic displays during courtship (Miller 2000). The suggestion made by Miller (2000) is that the status of moral behaviour helps to attract mates, because it may reflect fitness as the moral behaviour may have costs. In turn, the same effects may influence aesthetic judgements. 
Miller $(2000,2001)$ also suggests that art, language, and creativity can be explained by sexual selection, and that they are difficult to account for by survival selection. He suggests that art develops from courtship ornamentation, and uses bowerbirds as an evolutionary example. Male bowerbirds ornament their often enormous and structurally elaborate nests or bowers with mosses, ferns, shells, berries, and bark to attract female bowerbirds. The nests are used just to attract females, and after insemination the females go off and build their own cup-shaped nests, lay their eggs, and raise their offspring by themselves with no male support. In this sense, the bowers are useless ornamentation that do not have survival value. Darwin (1871) himself viewed human ornamentation and clothing as outcomes of sexual selection. Sexual selection for artistic ability does not mean of course that the art itself needs to be about sex. This example helps to show that sexual selection can lead to changes in what is valued and found attractive, in areas that might be precursors to art in humans. In Miller's (2001) view, the fine arts are just the most recent and pretentious manifestations of a universal human instinct for visual self-ornamentation, which in turn is a manifestation of sexual selection's universal tendency to ornament individuals with visual advertisements of their fitness. Thus, the human capacity for visual artistry is viewed as a 'fitness indicator', evolved like the peacock's tail and the bowerbird's bower for a courtship function. So although inherently useless, the bower or work of art is seen as attractive because it is difficult to produce, and might only be made by a brain that is very competent in general, and thus the bower or work of art may act as a fitness indicator.

A useful point (Miller 2001) is that although artworks are now commodified and spread wide so that we may not know the artist producing the ornament, when we seek the evolutionary origins of art, we should remember that any artwork our prehistoric ancestors would have been able to see, would have probably been made by a living individual with whom they could have interacted socially or sexually. The artist was never far from his or her work, or else the work could not have functioned as the artist's extended phenotype.

Miller (2000) also suggests that language evolved as a courtship device in males to attract females. Miller (2000) further suggests that creativity may be related to systems that can explore random new ideas, and also is a courtship device in males to attract females. My view, elaborated here and elsewhere (Rolls 2005b, 2008b; Rolls and Deco 2010), is that language and creativity have functions that have survival value, and thus are not just sexually selected.

Indeed, a criticism of the approach of Miller (2000) is that many of these characteristics (e.g., language, creative solutions, originality, problem-solving) may have survival value, and are not purely or primarily sexually selected. For example, syntax and language have many uses in problem-solving, planning ahead, and correcting multiple step plans that are likely to be very important to enable immediate rewards to be deferred, and longer-term goals to be achieved (Pinker and Bloom, 1992; Rolls, 2005b, 2008b). In relation to aesthetics, I argue that when syntax is used successfully to solve a difficult problem, we feel aesthetic pleasure, and I argue that the generation 
of pleasure generated by the survival value of good ideas contributes to the appeal of those ideas, and that sexual selection of the ideas as mental ornaments is not the only process at work in aesthetics.

Moreover, the notion (Miller 2000, 2001) that art has to do with useless ornaments (useless in the sense that sexual selection is for characteristics that may not have 'survival' value, but may be attractive because they are 'indicators of fitness') does not have much to say about the utilitarian arts such as simplicity of design in architecture. Perhaps the structure of a piece of music can appeal, and be pleasing, because it taps into our syntactic system that finds that elegant and simple solutions to problemsolving produce pleasure. As I argue elsewhere in this chapter, interest in social relations and knowledge about them is adaptive as it may help to understand who is doing what to whom, and more generally to understand what can happen to people, and much fictional literature addresses these issues, and is not primarily ornamental and without inherent value. Thus although Miller $(2000,2001)$ may well be right that there are aspects of art that may be primarily ornamental and useless, and are just indicators of general mental fitness, though attractive to members of the opposite sex in courtship, I suggest that much art has its roots in goals that have been specified as pleasurable or unpleasurable because of their adaptive or survival value, whether as primary reinforcers, other stimuli associated by learning with these, or rewards of a more cognitive origin that accrue when difficult cognitive, syntactic, problems are solved (see Table 8.1).

Another problem with Miller's approach is that traits that become sexually selected often have survival value in the first place, so it is often not possible to fully dissociate sexual selection from survival or adaptation selection (Andersson 1994; Andersson and Simmons 2006).

Another potential problem with Miller's approach is that some of the processes involved in sexual selection favour fast runaway evolution, because sexual preferences are genetically correlated with the ornaments they favour (see Section 5.3). Why does mental capacity not develop more rapidly, and with larger sex differences, in humans, if Miller (2000) is right? Why is there not a faster runaway? Miller suggests a number of possible reasons.

1. There is a high genetic correlation between human males and females, with $22 / 23$ chromosomes the same.

2. The female's brain must evolve to be able to appreciate the male's mental adornment - and might even be one step ahead to judge effectively. Further, similar or partly overlapping brain mechanisms may be used to produce (in males) and perceive (in females). In addition, male self-monitoring (and female practice) may help appraisal. Males may even internalize females' appreciation systems, to predict their responses.

3. There is mutual choice in humans: males choose females because human males do make a parental investment; and females compete for males. Indeed, the 
selection of a long-term partner is mutual, and this tends to reduce sex differences. Consistent with this, Buss $(1989,1999)$ has shown that, in contrast, human sex differences are more evident in short-term mating. It is likely in fact that sexual selection works mainly through long-term relationships, because of concealed ovulation in women. This means that only in a relatively long-term relationship is it likely that a man will become the father of a woman's child, because only if he mates with her regularly is there a reasonable probability that he will hit her fertile time.

Miller might predict that men should be specialized to have artistic creativity, to provide an ornament that women might find attractive because it is a fitness indicator. Evidence on this is difficult to evaluate, because there have been fewer opportunities available for women in the past, as argued for so beautifully by Virginia Woolf in A Room of One's Own (1928), and I come to no conclusions, but have the following thoughts. Whereas Virginia Woolf argues about circumstances, one can consider in addition the possibility that women's and men's brains have been subject to different selective pressure in evolution, and that this might contribute to differences in the ways in which they are creative. In terms of artists, composers of music, poets, and writers of drama and non-fiction, there appears to be on average a preponderance of men relative to women. This is on average, and there are individual women who given the distribution around the average are undoubtedly highly creative in these areas, and have made enormous contributions. If this is the case (and it might take a long time into the future to know, given the imbalance of opportunity in the past), does this mean that sexual selection is the underlying process? I suggest that this would not necessarily be the case. Such a 'sexual dimorphism' could occur by natural (adaptation) selection, not by sexual selection, in that women might have specialized for an environmental niche to emphasize child rearing, cultivation including food gathering and preparation, fashioning of clothing, and creating peaceful order among siblings and parents. On the other hand, men might have specialized for an environmental niche to emphasize spatial problem-solving, useful for producing and using tools, building shelters, creating structures, etc., and navigational problem-solving useful for hunting, all of which would be good for survival. Interestingly, the same (narrow) natural selection pressure might have provided a survival advantage for men to have a stronger physique which is likely be advantageous when manufacturing items useful for survival such as shelters. Thus interestingly, one of the predictions of sexual selection, sexual dimorphism, including human mental problem-solving as well as physique, could in this case have its origin at least partly in adaptation and survival.

There is, however, a possible exception to the generalization that at least in the past men have been more likely to be creative in 'art' than women, and this is the area of literary fiction, where there are many women with high reputations as novelists (e.g., Jane Austen, George Eliot, Virginia Woolf). If women take more to this area of creative art, might this be because of the adaptive value of gossip to women, so 
knowing about who is doing what to whom, and having an interest and expertise in this, could be adaptive, perhaps helping a woman, and her children, to survive better (Dunbar 1996)? If this were the case, there might even be a prediction that women might be relatively more excellent, on average, in areas of fiction, such as novels, where this interest and expertise in mind-reading and gossip might be especially engaged. (The fact that autism, which is associated with problems with mind reading, is several times more prevalent in men than in women (Baron-Cohen 2008) does fit with this general approach about adaptations suitable for different environmental niches.) More generally, the evolutionary survival value approach might argue that women have adapted to relational, social, caring, and problem-solving activities, and the novel, particularly the novel of manners, is ideally suited to displaying these specializations. Indeed, the specialization for a caring role is consonant with Carol Gilligan's argument in In a Different Voice (1982: 73) that women's sense of morality concerns itself with the activity of 'care and responsibility in relationships'.

The overall point I make is that natural selection, sometimes operating by 'survival or adaptation selection', and sometimes by sexual selection (and sometimes both, see above), operates by specifying goals for action, and these goals are aesthetically and subjectively attractive or beautiful (Rolls 2005b), or the opposite, and provide what I argue here is the origin of many judgements of what is aesthetic. Many examples of these rewards and punishers, many of which operate for 'survival or adaptation selection', and many of which contribute to aesthetic experience and judgements, are shown in Table 8.1.

\subsection{Fashion and memes}

We have seen that sexual selection can provide runaway selective pressure for what is not something that is produced by 'survival or adaptation' selection. In a sense, a fashion or useless ornament (which may indicate fitness) can be selected for genetically.

However, fashions are strong characteristics of many human aesthetic judgements, and we may ask if there are further reasons for this that are not to do with genetic variation (which necessarily takes place over generations), but that operate over timescales of months to years. Such fashions (for example in clothing) may occur because they fit adaptations of the human mind, themselves the result of adaptive pressure in evolutionary history. For example, the human mind will be attracted towards new ideas (of clear adaptive value, for it is only by exploring new ideas that advantage may be gained partly as a result of finding a match with one's own genetically influenced capacities) (Rolls 2005b). In this way, there may be runaway changes that do not necessarily make the individual better adapted to the environment. Of course, many factors, again frequently of evolutionary origin, influence fashion, including its cost (of which the label is an indicator), which helps to make it attractive as it indicates wealth, resources, and status, and the elegance and simplicity of the idea, which as argued below, the human mind finds attractive because simplicity often is a good indicator of a 
correct and useful solution to a problem. It is argued that memes (Blackmore 1999), ideas that follow some of the rules of fashion, fit these properties of the human mind.

\subsection{The elegance and beauty of ideas, and solving problems in the reasoning system}

Solving difficult problems feels good, and we often speak about elegant (and beautiful) solutions. What is the origin of the pleasure we obtain from elegant ideas? What makes them aesthetically pleasing? It is suggested that solving problems should feel good to us, to make us keep trying, as being able to solve difficult problems that require syntactic operations may have survival value (Rolls 2005b). But what is it that makes simple ideas and solutions (those with fewest premises, fewest steps to the solution, and fewest exceptions for a given level of complexity of a problem) particularly aesthetically pleasing, so much so that physicists may use this as a guide to their thinking? It is suggested that the human brain has become adapted to find simple solutions aesthetically pleasing because they are more likely to be correct (Rolls 2005b), and this is exactly the thrust of parsimony and Occam's Razor. (Occam's Razor is the principle or heuristic that entities and hypotheses should not be multiplied needlessly; the simplest of two competing and otherwise equally effective theories is to be preferred. The principle states that the explanation of any phenomenon should make as few assumptions as possible, eliminating those that make no difference in the observable predictions of the explanation or theory.)

This finds expression in art: for example in the structure of a piece of music; in the solution of how to incorporate perspective into painting (which took hundreds of years and was helped by the camera obscura); and in the interest by Vitruvius and Leonardo in the proportions of the human body (tapping into our gene-based appreciation of that) to provide rules for proportions in architecture. Of course, focus on intellectual aspects of art can lead to art that we may find fascinating and revealing, if not conventionally physically beautiful, as in some of the work of Francis Bacon. Factors such as cultural heritage and familiarity with the rules of a system can also make a style of architecture more appealing than something very unfamiliar. Some of the history of ecclesiastical architecture in England from the eleventh to the fifteenth century (from Norman through Early English and Decorated to Perpendicular) can also be seen as solutions to difficult architectural problems, of how to increase the light and feeling of space in a building, and its impression of grand and daring height.

\subsection{Cognition and aesthetics}

Not only can operation of our reasoning, syntactic, explicit, system lead to pleasure and aesthetic value, as just described, but also this cognitive system can modulate activity in the emotional, implicit, gene-identified goal system. This cognitive modulation, from the level of word descriptions, can have modulatory effects right down into the first cortical area, the orbitofrontal cortex, where affective value, including aesthetic value, such as the beauty in a face, is first made explicit in the representation (O'Doherty et al. 2003; De Araujo et al. 2005; Grabenhorst et al. 2008; McCabe et al. 2008; Rolls and 
Grabenhorst 2008). Indeed, cognition and attention can be used to enhance the emotional aspect of aesthetic experience, as described in Section 5.1.

The human mind may create objects such as sculpture and painting in ways that depend to different extents on the explicit reasoning system and the more implicit emotional system. I know at least one sculptor who intentionally reduces cognitive processing by turning off attention to cognitive processing when creating works of art, and then follows this with an explicit, conscious, reasoning stage in which selections and further changes may be made, with the whole creation involving very many such cycles.

Because cognition can by top-down cortico-cortical back projections influence representations at lower levels, it is possible that training, including cognitive guidance, can help to make more separate the representations of the representations of stimuli and their reward value at early levels of cortical processing (Rolls 2008b; Rolls and Treves 1998; Rolls and Deco 2002). This top-down effect may add to the bottom-up effects of self-organization in competitive networks that also through repeated training help representations of stimuli to be separated from and made more different to each other (Rolls 2008b; Rolls and Treves 1998; Rolls and Deco 2002). These effects may be important in many aesthetic judgements that are affected by training, including the appreciation of fine art, architecture, and wine.

\subsection{Wealth, power, resources, and reputation}

As described above, wealth, power, resources, and status are attractive qualities, aesthetically attractive, because resources are likely to be beneficial to the survival of genes. Reputation is similar, in that guarding one's reputation can be important in reproductive success: trust is important in a mate, or in reciprocal altruism, and hormones such as oxytocin may contribute to trust (Lee et al. 2009). This provides some insight into the history of Western art, in which individual and family portraits frequently have as one of their aims the portrayal of wealth, power, and resources. The clothes and background are consistent with a contribution of these underlying origins. Commissioned portraits thus frequently emphasize beauty, status, wealth, and resources. Interestingly, because self-portraits are rarely commissioned, they are less likely to emphasize these characteristics (Cumming 2009), and of course can also reflect subjective knowledge of the person portrayed. An additional property that can add value judged as aesthetic to a portrait is that an image of someone dear is associated with that person, and what that person means to the viewer, and the attraction of photographic images illustrates this. Religion and its accompanying states aiming often at everlasting happiness must also be recognized as drivers of art.

\subsection{The beauty of scenery and places}

Many topological features of landscapes may be aesthetically attractive because they tap into brain systems that evolved to provide signals of safety, food, etc. Open space may be attractive because potential predators can be seen; cover may be attractive as a place 
to hide (Appleton 1975); a verdant landscape may be attractive because it indicates abundant food; flowers may be attractive as predictors of fruit later in the season. The colour blue is preferred by monkeys, and this may be because blue sky, seen from the canopy, is an indicator of a safe place away from predators on the ground (Humphrey 1971). A clear red/orange sunset may be attractive as a predictor of good weather, and of safety overnight without bad weather. These factors do not operate alone to produce beauty, but may as origins contribute to aesthetic beauty which I argue is multifactorial, influenced by many of the factors described in this theory of the origin of aesthetics.

\subsection{The beauty of music}

Vocalization is used for emotional communication between humans, with an origin evident in other primates (Rolls et al. 2006). Examples include warning calls, warlike encouragement to action, and a soothing lullaby or song to an infant. It is suggested that this emotional communication channel is tapped into by music, and indeed consonant vs. dissonant sounds differentially activate the orbitofrontal cortex (Blood et al. 1999; Blood and Zatorre 2001), involved in emotion (Rolls 2005b). Of course, the reasoning system then provides its own input to the development, pleasure, and aesthetic value of music, in ways described in Sections 5.10 and 5.11.

What may underlie the greater pleasure and aesthetic value that many people accord to consonant vs. dissonant music? I suggest that consonance is generally pleasant because it is associated with natural including vocal sounds with a single source that naturally has harmonics. A good example is a calm female voice. Dissonance may often occur when there are multiple unrelated sources, such as those that might be produced by a catastrophe such as an earthquake, or boulders grinding against each other (or strings on a violin that are not tuned to be harmonics of each other). Further, a human voice when angry might have non-linearities, in for example the vocal cords due to over-exertion, and these may be harmonically much less pure than when the voice is calm and softer.

\subsection{Beauty, pleasure, and pain}

If a mildly unpleasant stimulus is added to a pleasant stimulus, sometimes the overall pleasantness of the stimulus, its attractive value, and perhaps its beauty, can be enhanced. A striking example is the sweet, floral scent of jasmine, which as it occurs naturally in Jasminum grandiflorum contains typically $2-3$ per cent of indole, a pure chemical which on its own at the same concentration is usually rated as unpleasant. The mixture can, at least in some people (and this may depend on their olfactory sensitivity to the different components), increase the pleasantness of the jasmine compared to the same odour without the indole. Why might this occur? One investigation has shown that parts of the brain such as the medial orbitofrontal cortex that represent the pleasantness of odors (Anderson et al. 2003; Rolls et al. 2003b; Grabenhorst and Rolls 2009) can respond even more strongly to jasmine when it contains the unpleasant 
component indole, compared to when it only contains individually pleasant components (Grabenhorst et al. 2007). Thus one brain mechanism that may underlie the enhancement effect is a principle that brain areas that represent the pleasantness of stimuli can do this in a way that is at least partly independent of unpleasant components, thereby emphasizing the pleasant component of a hedonically complex mixture.

A second factor that may contribute to the enhanced pleasantness of the mixture of jasmine and indole is that the indole may produce a contrast effect in the brain areas that represent the pleasant components of the mixture. An indication of this was found in increased activations in the medial orbitofrontal cortex (which represents the pleasantness of many stimuli) when the jasmine-indole mixture was being applied, compared to just the jasmine alone (Grabenhorst et al. 2007). To the extent that the pleasantness representation may drive hedonic experience separately from unpleasantness representations (Grabenhorst et al. 2007), and this might be facilitated by paying attention selectively to the pleasantness of a stimulus vs. its unpleasantness (Rolls et al. 2008), then a factor might be the increased activation of pleasantness representations if there is a component to the stimulus that is unpleasant, and can enhance the pleasantness representation by a contrast effect. Another example of pleasantness enhancement of pleasant by unpleasant stimuli occurs when an odour become more pleasant if it is preceded by an unpleasant (compared to a pleasant) odour, an effect represented in the human orbitofrontal cortex (Grabenhorst and Rolls 2009).

A third factor is that the interaction between the pleasant (jasmine) and unpleasant (indole) components makes the complex hedonic mixture (jasmine + indole) capture attention (which in turn may enhance and prolong the activation of the brain by the complex hedonic mixture), and evidence for the capture of attentional mechanisms in the brain by the pleasant-unpleasant mixture has been found (Grabenhorst et al. 2011).

These principles may of course operate in most areas where pleasant and unpleasant stimuli combine. Examples might include the pleasure we get from demanding terrain (high cliffs, high mountains, high seas); from spicy food that activates capsaicin (hot somatosensory) as well as gustatory and olfactory receptors (Rolls 2007a); from tragedy in literature, though empathy makes a large contribution here; from difficult feats, such as those performed by Odysseus (Rolls and Deco 2010), etc.

Let us consider the paradox of tragedy. For Aristotle, tragedy purged one of anxieties (Herwitz 2008). Somehow the depiction of tragedy in drama, which raises unpleasant emotions such as sadness at the tragedy, can also as drama afford pleasure. Hume's explanation was that the beauty of the language and the eloquence of the artist's depictive talents are the source of pleasure (Hume 1757; Yanal 1991). Is there more to say about this? Schadenfreude, gloating pleasure at the distress of an envied person, is associated with activation of brain areas that respond to pleasant stimuli (ShamayTsoory et al. 2007; Takahashi et al. 2009), and I suggest is related to the evolutionary origin of competition between individuals, and winning the competition. It is probably not an important factor in the appreciation of tragedy in drama. What may be more important is first that we (and this is especially strong in women) always want to know 
what is happening to whom, and gossip has evolutionary value (Dunbar 1996) in that this can provide information about how others are likely to treat you, and more generally, about the things that can happen to people in life, and from which we can potentially learn. Second, the ability to empathize with another's emotions, and indeed to be good at this and find it rewarding, may also be important in communities, in order to facilitate kin or reciprocal altruism (Ridley 1996). Third, the ability to have a theory of other people's minds is adaptive in facilitating prediction of their behaviour (Frith and Singer 2008), and fascination with this should again in an evolutionary context be rewarding, and be associated with pleasure. It is suggested that these three factors are at least important contributors to the pleasure that people find in tragedy in drama. The same factors, I suggest, are also important contributors to the popularity of novels. In the cases of both drama and novels, we know that they are fiction, or at least are not happening to the spectator or reader, and this helps to make them particularly rewarding ways to learn about social relations and life events, because there is no risk to the spectator or reader.

Knowing that the work of art (music, literature, painting, sculpture) is a fiction may also account for why the 'aesthetic' emotions are not as long-lasting, and are not as motivating, as goals in real life.

\subsection{Absolute value in aesthetics and art}

The approach described here proposes that what we find aesthetic has its roots and origins in two main processes: gene-specified goals, rewards and punishers; and the value that is felt when our reasoning system produces, and understands, elegant and simple solutions to problems. What implications does this have for absolute aesthetic value? The implication is that while there is no absolute aesthetic value that is independent of these processes, we will nevertheless find considerable agreement between individuals, especially when the aesthetic value being judged has its roots in the two main processes described. However, as described here, there will be variation for good evolutionary reasons between what different individuals find of value, and there will be variation in individuals' thought processes caused by their cultural heritage, and by noise in the brain which is an important component to creativity (Rolls and Deco 2010). For these reasons, and because aesthetic value is multifactorial (i.e., is influenced by multiple conscious and unconscious processes), we must expect variation in aesthetic value across people, time, and place, with no absolute aesthetic value.

\section{Is what is attractive, beautiful and aesthetic?}

I wish to counter a possible objection to the theory of the origin of aesthetics described here. The possible objection is that some of the goals specified by our genes, such as the reward value and pleasantness of a high energy, high fat diet, might seem rather unsavoury, and not quite aesthetic. The point I make is that it is not just the 
gene-specified rewards and punishers that make stimuli have aesthetic value. My proposal is that the reasoning (rational) system also contributes to aesthetic value, in a number of ways. It makes rather longer-term goals attractive. It introduces the further goal that innovation is attractive, as this is likely to help solve difficult problems and move the person into a new part of state space where the person may have an advantage. It introduces the use of syntactic relational structure to provide another way of computation, and problem-solving with this reasoning system is encouraged by simple elegant solutions being rewarding and having aesthetic value, as described above. These factors would help the sophisticated structure in a Bach partita and fugue to contribute to what we judge as aesthetically pleasing, because such music taps not only into our emotional systems, but also into the systems that provide intellectual pleasure because difficult and complex structural problems are posed, and solutions to these difficult structural problems are provided, which as described provides aesthetic pleasure.

In this sense, aesthetic value may have its roots partly in gene-specified rewards (and punishers), but also in the pleasure that the rational system can provide when it is posed, and finds, elegant and simple solutions (which by parsimony are likely to be correct) to complex problems. For this reason, emotions may not be perfectly aligned with aesthetic value. Although both have their origin in gene-specified rewards, emotions may be produced by any one of a large number of reinforcers, whereas aesthetic value usually includes contributions of the reasoning (rational) system, as just described.

Art as a whole is a larger issue than aesthetics and beauty. The content of art might I suggest be seen as the result of multiple separate trajectories through a state space in which each trajectory is guided by the origins of aesthetics (products of adaptations for survival and of sexual selection for useless, sometimes handicapping ornament, and rational thought to develop structure in which an elegant and simple solution is pleasing), and depends on each previous trajectory, the history of art in each culture. Each trajectory is not itself deterministic, because it is influenced by noise (Rolls and Deco 2010) (as is Darwinian evolution). Thus the particular future trajectories cannot be predicted. In each trajectory though a number of factors guide, including new-ness (which is biologically attractive as argued above), wildness (as in Beethoven's late string quartets), as well as what we rationally find aesthetic (as described above), and what survival and sexual selection have also provided in us as some of the origins of aesthetics.

\section{Comparison with other theories of aesthetics}

Much research I have performed shows that there is a perceptual representation of objects formed in cortical areas that is kept separate from the representation of the affective value of objects, which happens further on in processing, in brain regions such as the orbitofrontal cortex (and in an area to which it projects, the anterior cingulate cortex) and the amygdala (see Fig. 8.2). For example, in the inferior temporal visual cortex there is a representation of objects that is independent of whether an object is 
associated with reward vs. punishment, or is made rewarding or not by hunger (Rolls et al. 1977, 2003a). In the primary taste cortex in the insula and frontal operculum, there is a representation of what taste is present, and of its intensity, that is independent of its reward value as altered by hunger vs. satiety, and that is correlated with the subjective intensity but not subjective pleasantness of taste (Rolls et al. 1988; Yaxley et al. 1988; Grabenhorst and Rolls 2008; Grabenhorst et al. 2008; Rolls et al. 2009). In the primary olfactory (pyriform) cortex, activations are correlated with the subjective intensity but not subjective pleasantness of odor (Rolls et al. 2003b, 2008, 2009). On the other hand, the affective value of taste, olfactory, visual, thermal, tactile, and auditory stimuli is represented in the orbitofrontal cortex. This is shown by neuronal responses that are modulated by hunger or occur to stimuli when they are associated with a reward, and by correlations of brain activations with subjective ratings of pleasantness but not intensity (Rolls et al. 1989; Critchley and Rolls 1996; Kringelbach et al. 2003; Rolls 2005b, 2007a; Rolls and Grabenhorst 2008; Rolls et al. 2009).

There are good functional and adaptive reasons for separate representations of objects and of their affective value. We can still see and recognize objects (including tastes, smell, the sight of objects, etc.) even when they are not rewarding to us, for example if they are foods and we are not hungry. (We do not go blind to objects when they are not rewarding or punishing.) Moreover, it is adaptive to be able to learn about where we have seen objects, people, etc., even if they are not currently rewarding, so that we can find them later when they are needed. Thus there is strong neuroscientific evidence, and sound biological arguments, for separate representations of perceptual objects and of their affective value. Baumgarten (1750) expressed this thought in his book Aesthetica when he suggested that sensation, the use of the five senses, is separate from sensibility, which is something more, a 'kind of intuition/cognition/formulation of the thing which judges it beautiful', and in doing so gave rise to the term aesthetics (Herwitz 2008). Before this, abstract questions such as 'What is beauty?' 'What is art?' had not been treated in philosophy, although before this Aristotle had discussed the social role of drama as purging us of ever-present anxiety, and Plato had dismissed poetry as obfuscating by sending the mind reeling into hypnotic trances instead of focusing on rational deductions and argument (Herwitz 2008).

David Hume (1777) takes a broad view of taste (which engages beauty), and argues for five standards of ('delicacy of') taste that might be shown by experts: 'Strong sense, united to delicate sentiment, improved by practice, perfected by comparison, and cleared of all prejudice, can alone entitle critics to this valuable character; and the joint verdict of such, wherever they are to be found, is the true standard of taste and beauty.' Hume's difficulty is that he believes taste is objective, because delicacy is the probing instrument for truth; but instead, taste is a circular and constructivist enterprise (Herwitz 2008). My approach has in contrast a clear foundation for aesthetics in brain function and its evolutionary design, with clear views about how it includes rational thought which provides its own pleasures, and about how art can idealize beyond the normal world by building on these foundations and origins. 
Immanuel Kant (1724-1804) distinguishes between liking something and finding it beautiful. According to Kant when I find a painting beautiful this is not conditioned by any causal relation between its properties and my pleasures. For Kant, a judgement of beauty carries the weight of 'ought', that others should judge it beautiful too, so his theory has moral implications. His judgement of beauty is a 'disinterested' judgement, one that is not peculiar to him. He wants the beauty to be in the person, but not causally dependent on the properties of the object in the world such as the pleasure it produces (Kant 1790). He thus appears to be committed to an objective and universal view of art, although exactly how this view is arrived at is not at all clear. The biological and neuroscientific view that I propose indicates that in contrast art is not universal or objective, but instead can be judged good art if it taps into many of the human rational and gene-based reward systems (see further Section 6), with therefore individual differences expected, as described in Section 5.16.

Darwin (1871) recognized that evolution can occur by sexual selection, when what is being selected for has no inherent adaptive or survival value, but is attractive to potential mates (inter-sexual selection), or helps in competing with others of the same sex (intra-sexual selection). His view was that natural beauty arose through competition to attract a sexual partner. His process of sexual selection through mate choicethe struggle to reproduce, not to survive-drove the evolution of visual ornamentation and artistry, from flowers through bird plumage to human self-adornment. Many have developed or ascribed to this idea (including Veblen 1899; Gombrich 1977; Zahavi 1978; and Dutton 2009; see Miller 2001), and Miller (2000, 2001) has proposed a sexual selection theory of art. The implication of this theory is that art has to do with what are frequently useless ornaments (useless in the sense that sexual selection is for characteristics that do not have 'survival' value, but are usually just attractive because they are handicaps and are indicators of fitness). I agree that useless handicapping ornament produced by sexual selection does play a role in aesthetics. However, the sexual selection theory does not therefore have much to say about the utilitarian arts such as simple design in architecture. Perhaps the structure of a piece of music can appeal, and be pleasing, because it taps into our syntactic system that finds that adaptive, survival value-related, elegant, and simple solutions to problem-solving produce pleasure. As I argued above, interest in social relations and knowledge about them is adaptive and has survival value as it may help to understand who is doing what to whom, and more generally to understand what can happen to people, and much fictional literature addresses these issues, and is not purely ornamental and without inherent value. Thus although Miller may well be right that there are aspects of art that may be primarily ornamental and useless, though attractive to members of the opposite sex in courtship, I suggest that much art has its roots in goals that have been specified as pleasurable or unpleasurable because of their 'survival or adaptive' value, whether as primary reinforcers, other stimuli associated by learning with these, or rewards of a more cognitive origin that accrue when difficult cognitive, syntactic, problems are 
solved. I also emphasize that some of the characteristics emphasised by sexual selection may have some inherent survival value (mechanisms i-ii in Section 5.3).

To end, my theory (Rolls' theory) of aesthetics thus specifies the roles of Darwinian 'survival or adaptive' selection and sexual selection in aesthetics. It is thus thoroughly Darwinian. A key idea is that many of the things that provide pleasure, or its opposite, do so because they are, or are related to, the gene-specified goals for action. Motivational states arise when trying to obtain these goals, and emotional or affective states when these goals are obtained, or are not obtained. These states are associated with affect and value, and with subjective pleasantness or unpleasantness, because it is an efficient way in which genes can influence their own (reproductive) success ('fitness'), and much more efficient and effective as a Darwinian process than prescribing that the animal should make particular responses to particular stimuli (Rolls 2005a). The theory is that aesthetic value has its roots partly in these gene-specified rewards that have survival or adaptive value; but also in the pleasure that the rational system can provide when it is posed, and finds, elegant and simple solutions (which by parsimony are likely to be correct and hence adaptive) to complex problems; and to some extent in sexual selection. What makes good art can be influenced by many factors, as described here, so is complex and multifaceted, and these factors must include whether the effect of the art is for good or for harm. It also follows that attempts in aesthetics to produce a systematic account based on consistent explicit beliefs will not succeed, for many factors that are not necessarily consistent with each other are involved in aesthetic values, and because some of these factors operate at least partly unconsciously and nonpropositionally/non-syntactically, that is, using computational systems in the brain that do not involve reasoning. ${ }^{4}$

\section{References}

Anderson, A. K., K. Christoff, I. Stappen, D. Panitz, D. G. Ghahremani, G. Glover, J. D. Gabrieli, and N. Sobel (2003). 'Dissociated Neural Representations of Intensity and Valence in Human Olfaction'. Nature Neuroscience, 6: 196-202.

Andersson, M. (1994). Sexual Selection. Princeton: Princeton University Press.

— and L. W. Simmons (2006). 'Sexual Selection and Mate Choice'. Trends in Ecology E Evolution (Personal Edition), 21: 296-302.

Appleton, J. (1975). The Experience of Landscape. New York: Wiley.

Baron-Cohen, S. (2008). Autism and Asperger Syndrome: The Facts. Oxford: Oxford University Press.

Barrett, L., R. Dunbar, and J. Lycett (2002). Human Evolutionary Psychology. Basingstoke: Palgrave Macmillan.

Baumgarten, A. G. (1750). Aesthetica.

Berger, J. (1972). Ways of Seeing. Harmondsworth: Penguin.

\footnotetext{
${ }^{4}$ I am grateful to M. S. Dawkins, B. K. Scott, and P. Wheatley for helpful discussions, and to Peter Goldie for good advice.
} 
Bertram, B. C. R. (1975). 'Social Factors Influencing Reproduction in Wild Lions'. Journal of Zoology, 177: 463-82.

Birkhead, T. (2000). Promiscuity. London: Faber and Faber.

Blackmore, S. J. (1999). The Meme Machine. Oxford: Oxford University Press.

Blood, A. J. and R. J. Zatorre (2001). 'Intensely Pleasurable Responses to Music Correlate With Activity in Brain Regions Implicated in Reward and Emotion'. Proceedings of the National Academy of Sciences of the United States of America, 98: 11818-23.

Blood, A. J., R. J. Zatorre, P. Bermudez, and A. C. Evans (1999). Emotional Responses to Pleasant and Unpleasant Music Correlate With Activity in Paralimbic Brain Regions'. Nature Neuroscience, 2: 382-7.

Buss, D. M. (1989). 'Sex Differences in Human Mate Preferences: Evoluntionary Hypotheses Tested in 37 Cultures'. Behavioural and Brain Sciences, 12: 1-14.

- (1999). Evolutionary Psychology: The New Science of the Mind. Boston, MA: Allyn and Bacon.

— (2006). 'Debating Sexual Selection and Mating Strategies'. Science, 312: 689-97.

—and D. P. Schmitt (1993). 'Sexual Strategies Theory: An Evolutionary Perspective on Human Mating'. Psychological Review, 100: 204-32.

Carter, C. S. (1998). 'Neuroendocrine Perspectives on Social Attachment and Love'. Psychoneuroendocrinology, 23: 779-818.

Critchley, H. D. and E. T. Rolls (1996). 'Hunger and Satiety Modify the Responses of Olfactory and Visual Neurons in the Primate Orbitofrontal Cortex'. Journal of Neurophysiology, 75: 1673-86.

Cumming, L. (2009). A Face to the World: On Self-Portraits. London: Harper.

Daly, M. and M. Wilson (1988). Homicide. New York: Aldine de Gruyter.

Damasio, A. R. (1994). Descartes' Error. New York: Putnam.

Darwin, C. (1871). The Descent of Man, and Selection in Relation to Sex. London: John Murray (reprinted in 1981 by Princeton University Press).

- (1872). The Expression of the Emotions in Man and Animals, 3rd ed. Chicago: University of Chicago Press.

Dawkins, M. S. (1995). Unravelling Animal Behaviour. Harlow: Longman.

Dawkins, R. (1986). The Blind Watchmaker. Harlow: Longman.

- (1989). The Selfish Gene, 2nd ed. Oxford: Oxford University Press.

de Araujo, I. E. T., E. T. Rolls, M. I. Velazco, C. Margot, and I. Cayeux (2005). 'Cognitive Modulation of Olfactory Processing'. Neuron, 46: 671-9.

De Vries, A. C., M. B. De Vries, S. E. Taymans, and C. S. Carter (1996). 'The Effects of Stress on Social Preferences are Sexually Dimorphic in Prairie Voles'. Proceedings of the National Academy of Sciences of the United States of America, 93: 11980-4.

Dulac, C. and A. T. Torello (2003). 'Molecular Detection of Pheromone Signals in Mammals: From Genes to Behaviour'. Nature Reviews, 4: 551-62.

Dunbar, R. (1996). Grooming, Gossip, and the Evolution of Language. London: Faber and Faber. Dutton, D. (2009). The Art Instinct. Oxford: Oxford University Press.

Ekman, P. (1982). Emotion in the Human Face, 2nd edn. Cambridge: Cambridge University Press. -(1993). 'Facial Expression and Emotion'. American Psychologist, 48: 384-92.

Fisher, R. A. (1930). The Genetical Theory of Natural Selection. Oxford: Clarendon Press (2nd edn. New York: Dover, 1958).

Frijda, N. H. (1986). The Emotions. Cambridge: Cambridge University Press. 
Frith, C. D. and T. Singer (2008). 'The Role of Social cognition in Decision Making'. Philosophical Transactions of the Royal Society of London, 363: 3875-86.

Gangestad, S. W and J. A. Simpson (2000). 'The Evolution of Human Mating: Trade-offs and Strategic Pluralism'. Behavioral and Brain Sciences, 23: 573-87; discussion 587-644.

— and R. Thornhill (1999). 'Individual Differences in Developmental Precision and Fluctuating Asymmetry: A Model and its Implications'. Journal of Evolutionary Biology, 12: 402-16.

Gilligan, C. (1982). In a Different Voice. Cambridge, MA: Harvard University Press.

Gombrich, E. (1977). Art and Illusion: A Study in the Psychology of Pictorial Representation, 5th edn. London: Phaidon Press.

Grabenhorst, F. and E. T. Rolls (2008). 'Selective Attention to Affective Value Alters How the Brain Processes Taste Stimuli'. European Journal of Neuroscience, 27: 723-9.

(2009). 'Different Representations of Relative and Absolute Value in the Human Brain'. NeuroImage, 48: 258-68.

(2011). 'Value, Pleasure, and Choice Systems in the Ventral Prefrontal Cortex'. Trends in Cognitive Sciences, 15: 56-67.

and A. Bilderbeck (2008). 'How Cognition Modulates Affective Responses to Taste and Flavor: Top-down Influences on the Orbitofrontal and Pregenual Cingulate Cortices'. Cerebral Cortex, 18: 1549-59. and C. Margot (2011). 'A Hedonically Complex Odor Mixture Captures the Brain's Attention'. NeuroImage, 55: 832-43.

M. A. A. P. Da Silva, and M. I. Velazco (2007). 'How Pleasant and Unpleasant

Stimuli Combine in Different Brain Regions: Odor Mixtures'. Journal of Neuroscience, 27: 13532-40.

Grafen, A. (1990a). 'Biological Signals as Handicaps'. Journal of Theoretical Biology, 144: 517-46.

- (1990b). 'Sexual Selection Unhandicapped by the Fisher Process'. Journal of Theoretical Biology, 144: 473-516.

Gray, J. A. (1975). Elements of a Two-Process Theory of Learning. London: Academic Press.

- (1987). The Psychology of Fear and Stress, 2nd edn. Cambridge: Cambridge University Press.

Hamilton, W. (1964). 'The Genetical Evolution of Social Behaviour'. Journal of Theoretical Biology, 7: 1-52.

Hamilton, W. D. (1996). Narrow Roads of Gene Land. New York: W. H. Freeman.

— and M. Zuk (1982). 'Heritable True Fitness and Bright Birds: A Role for Parasites?' Science, 218: $384-7$.

Herwitz, D. (2008). Aesthetics. London: Continuum.

Hume, D. (1757). Four Dissertations: Of Tragedy.

- (1777). Selected Essays: Of the Standard of Taste.

Humphrey, N. (1971). 'Colour and Brightness Preferences in Monkeys'. Nature, 229: 615-17.

Johnston, V. S. and M. Franklin (1993). 'Is Beauty in the Eye of the Beholder?' Ethology and Sociobiology, 14: 183-99.

Kant, I. (1790). Critique of Judgement.

Kappeler, P. M. and C. P. Van Schaik (2004). 'Sexual Selection in Primates: Review and Selective Preview', in P. M. Kappeler and C. P. Van Schaik (eds.), Sexual Selection in Primates. Cambridge: Cambridge University Press, pp. 3-23.

Keverne, E. B., C. M. Nevison, and F. L. Martel (1997). 'Early Learning and the Social Bond'. Annals of the New York Academy of Science, 807: 329-39. 
Kringelbach, M. L., J. O'Doherty, E. T. Rolls, and C. Andrews (2003). 'Activation of the Human Orbitofrontal Cortex to a Liquid Food Stimulus is Correlated with its Subjective Pleasantness'. Cerebral Cortex, 13: 1064-71.

Krug, R., W. Plihal, H. L. Fehm, and J. Born (2000). 'Selective Influence of the Menstrual Cycle on Perception of Stimuli with Reproductive Significance: An Event-Related Potential Study'. Psychophysiology, 37: 111-22.

Kruger, T. H. C., P. Haake, D. Chereath, W. Knapp, O. E. Janssen, M. S. Exton, M. Schedlowski, and U. Hartmann (2003). 'Specificity of the Neuroendocrine Response to Orgasm during Sexual Arousal in Men'. Journal of Endocrinology, 177: 57-64.

Langlois, J. H., L. Kalakanis, A. J. Rubenstein, A. Larson, M. Hallam, and M. Smoot (2000). 'Maxims or Myths of Beauty? A Meta-Analytic and Theoretical Review'. Psychological Bulletin, 126: 390-423.

-J. M. Ritter, L. A. Roggman, and L. S. Vaughn (1991). 'Facial Diversity and Infant Preferences for Attractive Faces'. Developmental Psychology, 27: 79-84.

- L. A. Roggman, and L. A. Rieserdanner (1990). 'Infants Differential Social Responses to Attractive and Unattractive Faces'. Developmental Psychology, 26: 153-9.

-R. J. Casey, J. M. Ritter, L. A. Rieserdanner, and V. Y. Jenkins (1987). 'Infant Preferences for Attractive Faces: Rudiments of a Stereotype'. Developmental Psychology, 23: 363-9.

Lazarus, R. S. (1991). Emotion and Adaptation. New York: Oxford University Press.

Lee, H. J., A. H. Macbeth, J. H. Pagani, and W. S. Young Iii (2009). 'Oxytocin: The Great Facilitator of Life'. Progress in Neurobiology, 88: 127-51.

Lim, M. M., Z. X. Wang, D. E. Olazabal, X. H. Ren, E. F. Terwilliger, and L. J. Young (2004). 'Enhanced Partner Preference in a Promiscuous Species by Manipulating the Expression of a Single Gene'. Nature, 429: 754-7.

Maia, T. V. and J. L. McClelland (2004). 'A Reexamination of the Evidence for the Somatic Marker Hypothesis: What Participants Really Know in the Iowa Gambling Task'. Proceedings of the National Academy of Sciences of the United States of America, 101: 16075-80.

Maynard Smith, J. and D. Harper (2003). Animal Signals. Oxford: Oxford University Press.

McCabe, C., E. T. Rolls, A. Bilderbeck, and F. McGlone (2008). 'Cognitive Influences on the Affective Representation of Touch and the Sight of Touch in the Human Brain'. Social, Cognitive and Affective Neuroscience, 3: 97-108.

Mead, L. S. and S. J. Arnold (2004). 'Quantitative Genetic Models of Sexual Selection'. Trends in Ecology \& Evolution (Personal Edition), 19: 264-71.

Meston, C. M. and P. F. Frohlich (2000). 'The Neurobiology of Sexual Function'. Archives of General Psychiatry, 57: 1012-30.

Millenson, J. R. (1967). Principles of Behavioral Analysis. New York: Macmillan.

Miller, G. F. (2000). The Mating Mind. London: Heinemann.

- (2001). 'Aesthetic Fitness: How Sexual Selection Shaped Artistic Virtuosity as a Fitness Indicator and Aesthetic Preferences as Mate Choice Criteria'. Bulletin of Psychology and the Arts, 2: $20-5$.

O'Doherty, J., J. Winston, H. Critchley, D. Perrett, D. M. Burt, and R. J. Dolan (2003). 'Beauty in a Smile: The Role of Medial Orbitofrontal Cortex in Facial Attractiveness'. Neuropsychologia, 41: 147-55.

Oatley, K. and J. M. Jenkins (1996). Understanding Emotions. Oxford: Blackwell. 
Penton-Voak, I. S., D. I. Perrett, D. L. Castles, T. Kobayashi, D. M. Burt, L. K. Murray, and R. Minamisawa (1999). 'Menstrual Cycle Alters Face Preference'. Nature, 399: 741-2.

Pinker, S. and P. Bloom (1992). 'Natural Language and Natural Selection', in J. H. Barkow, L. Cosmides, and J. Tooby (eds.), The Adapted Mind. New York: Oxford University Press, pp. 451-93.

Pizzari, T., C. K. Cornwallis, H. Lovlie, S. Jakobsson, and T. R. Birkhead (2003). 'Sophisticated Sperm Allocation in Male Fowl'. Nature, 426: 70-4.

Ridley, M. (1996). The Origins of Virtue. London: Viking.

Rolls, E. T. (1986a). 'Neural Systems Involved in Emotion in Primates', in R. Plutchik and H. Kellerman (eds.), Emotion: Theory, Research, and Experience. Vol. 3. Biological Foundations of Emotion. New York: Academic Press, pp. 125-43.

- (1986b). 'A Theory of Emotion, and its Application to Understanding the Neural Basis of Emotion', in Y. Oomura (ed.), Emotions. Neural and Chemical Control. Basel: Karger, pp. 325-44.

- (1990). 'A Theory of Emotion, and its Application to Understanding the Neural Basis of Emotion'. Cognition and Emotion, 4: 161-90.

- (1999). The Brain and Emotion. Oxford: Oxford University Press.

- (2000). 'Précis of The Brain and Emotion'. Behavioral and Brain Sciences, 23: 177-233.

- (2003). 'Consciousness Absent and Present: A Neurophysiological Exploration'. Progress in Brain Research, 144: 95-106.

- (2004). 'A Higher Order Syntactic Thought (HOST) Theory Of Consciousness', in

R. J. Gennaro (ed.), Higher-Order Theories of Consciousness: An Anthology. Amsterdam: John Benjamins, pp. 137-72.

- (2005a). 'Consciousness Absent or Present: A Neurophysiological Exploration of Masking', in H. Ogmen and B. G. Breitmeyer (eds.), The First Half Second: The Microgenesis and Temporal Dynamics of Unconscious and Conscious Visual Processes. Cambridge, MA: MIT Press, pp. 89-108. - (2005b). Emotion Explained. Oxford: Oxford University Press.

- (2007a). 'The Representation of Information about Faces in the Temporal and Frontal Lobes'. Neuropsychologia, 45: 125-43.

- (2007b). 'A Computational Neuroscience Approach to Consciousness'. Neural Networks, 20: $962-82$.

- (2007c). 'The Affective Neuroscience of Consciousness: Higher Order Linguistic Thoughts, Dual Routes to Emotion and Action, and Consciousness', in P. Zelazo, M. Moscovitch, and E. Thompson (eds.), Cambridge Handbook of Consciousness. Cambridge: Cambridge University Press, pp. 831-59.

- (2007d). 'Sensory Processing in the Brain Related to the Control of Food Intake'. Proceedings of the Nutrition Society, 66: 96-112.

-(2008a). Memory, Attention, and Decision-Making: A Unifying Computational Neuroscience Approach. Oxford: Oxford University Press.

- (2008b). 'Emotion, Higher Order Syntactic Thoughts, and Consciousness', in L.

Weiskrantz and M. K. Davies (eds.), Frontiers of Consciousness. Oxford: Oxford University Press, pp. 131-67.

- (2009). 'The Anterior and Midcingulate Cortices and Reward', in B. A. Vogt (ed.),

Cingulate Neurobiology and Disease. Oxford: Oxford University Press, pp. 191-206.

- (2011a). Neuroculture. Oxford: Oxford University Press. 
- (2011b). 'Consciousness, Decision-Making, and Neural Computation', in V. Cutsuridis, A. Hussain, and J. G. Taylor (eds.), Perception-Action Cycle: Models, Algorithms and Systems. Berlin: Springer, 287-333

— and G. Deco (2002). Computational Neuroscience of Vision. Oxford: Oxford University Press. (2010). The Noisy Brain: Stochastic Dynamics as a Principle of Brain Function. Oxford:

Oxford University Press.

—and F. Grabenhorst (2008). 'The Orbitofrontal Cortex and Beyond: From Affect to Decision-Making'. Progress in Neurobiology, 86: 216-44.

- and S. M. Stringer (2001). 'A Model of the Interaction between Mood and Memory'. Network: Computation in Neural Systems, 12: 111-29.

— and A. Treves (1998). Neural Networks and Brain Function. Oxford: Oxford University Press. -N. C. Aggelopoulos, and F. Zheng (2003a). 'The Receptive Fields of Inferior Temporal Cortex Neurons in Natural Scenes'. Journal of Neuroscience, 23: 339-48.

-H. D. Critchley, A. S. Browning, and K. Inoue (2006). 'Face-Selective and Auditory Neurons in the Primate Orbitofrontal Cortex'. Experimental Brain Research, 170: 74-87.

J. V. Verhagen, and M. Kadohisa (2009). 'The Representation of Information about

Taste and Odor in the Orbitofrontal Cortex'. Chemosensory Perception, 3: 16-33.

-F. Grabenhorst, C. Margot, M. A. A. P. da Silva, and M. I. Velazco (2008). 'Selective Attention to Affective Value Alters How the Brain Processes Olfactory Stimuli'. Journal of Cognitive Neuroscience, 20: 1815-26.

- S. J. Judge, and M. Sanghera (1977). 'Activity of Neurones in the Inferotemporal Cortex of the Alert Monkey'. Brain Research, 130: 229-38.

- M. L. Kringelbach, and I. E. T. de Araujo (2003b). 'Different Representations of Pleasant and Unpleasant Odors in the Human Brain'. European Journal of Neuroscience, 18: 695-703.

— T. R. Scott, Z. J. Sienkiewicz, and S. Yaxley (1988). 'The Responsiveness of Neurones in the Frontal Opercular Gustatory Cortex of the Macaque Monkey is Independent of Hunger'. Journal of Physiology, 397: 1-12.

-Z. J. Sienkiewicz and S. Yaxley (1989). 'Hunger Modulates the Responses to Gustatory Stimuli of Single Neurons in the Caudolateral Orbitofrontal Cortex of the Macaque Monkey'. European Journal of Neuroscience, 1: 53-60.

Ryan, M. J. (1998). 'Sexual Selection, Receiver Biases, and the Evolution of Sex Differences'. Science, 281: 1999-2003.

Shamay-Tsoory, S. G., Y. Tibi-Elhanany, and J. Aharon-Peretz (2007). 'The Green-Eyed Monster and Malicious Joy: The Neuroanatomical Bases of Envy and Gloating (Schadenfreude)'. Brain, 130: 1663-78

Singh, D. and P. M. Bronstad (2001). 'Female Body Odour is a Potential Cue to Ovulation'. Proceedings of the Royal Society B-Biological Sciences, 268: 797-801.

— and S. Luis (1995). 'Ethnic and Gender Consensus for the Effect of Waist-to-Hip Ratio on Judgment of Women's Attractiveness'. Human Nature: An Interdisciplinary Biosocial Perspective, 6: 51-65.

—W. Meyer, R. J. Zambarano, D. Farley, and D. F. Hurlbert (1998). 'Frequency and Timing of Coital Orgasm in Women Desirous of Becoming Pregnant'. Archives of Sexual Behavior, 27: 15-29.

Strongman, K. T. (1996). The Psychology of Emotion, 4th edn. London: Wiley. 
Swaddle, J. P. and G. W. Reierson (2002). 'Testosterone Increases Perceived Dominance But Not Attractiveness in Human Males'. Proceedings of the Royal Society: Biological Sciences, 269: 2285-9.

Takahashi, H., M. Kato, M. Matsuura, D. Mobbs, T. Suhara, and Y. Okubo (2009). 'When Your Gain is My Pain and Your Pain is My Gain: Neural Correlates of Envy and Schadenfreude'. Science, 323: 937-9.

Thornhill, R. and S. W. Gangestad (1999). 'Facial Attractiveness'. Trends in Cognitive Science, 3: 452-60.

—and K. Grammer (1999). 'The Body and Face of Woman: One Ornament that Signals Quality?' Evolution and Human Behavior, 20: 105-20.

Trivers, R. L. (1971). 'Evolution of Reciprocal Altruism'. Quarterly Review of Biology, 46: 35-57.

- (1974). 'Parent-Offspring Conflict'. American Zoologist, 14: 249-64.

Uvnas-Moberg, K. (1998). 'Oxytocin May Mediate the Benefits of Positive Social Interaction and Emotions'. Psychoneuroendocrinology, 23: 819-35.

Vandenberghe, P. L. and P. Frost (1986). 'Skin Color Preference, Sexual Dimorphism and Sexual Selection: A Case of Gene Culture Coevolution'. Ethnic and Racial Studies, 9: 87-113.

Veblen, T. (1899). The Theory of the Leisure Class. New York: Macmillan.

Weiskrantz, L. (1968). 'Emotion', in L. Weiskrantz (ed.), Analysis of Behavioural Change. New York and London: Harper \& Row, pp. 50-90.

Winslow, J. T. and T. R. Insel (2004). 'Neuroendocrine Basis of Social Recognition'. Current Opinion in Neurobiology, 14: 248-53.

Woolf, V. (1928). A Room of One's Own.

Wynne-Edwards, K. E. (2001). 'Hormonal Changes in Mammalian Fathers'. Hormones and Behavior, 40: 139-45.

Yanal, R. J. (1991). 'Hume and Others on the Paradox of Tragedy'. Journal of Aesthetics and Art Criticism, 49: 75-6.

Yaxley, S., E. T. Rolls, and Z. J. Sienkiewicz (1988). 'The Responsiveness of Neurons in the Insular Gustatory Cortex of the Macaque Monkey is Independent of Hunger'. Physiology and Behavior, 42: 223-9.

Young, L. J. (2008). 'Molecular Neurobiology of the Social Brain'. Hormones and Social Behavior, 198: 57-64.

Zahavi, A. (1975). 'Mate Selection: A Selection for a Handicap'. Journal of Theoretical Biology, 53: 205-14.

— (1978). 'Decorative Patterns and the Evolution of Art'. New Scientist, 19: 182-4. 
